\title{
Bewahrung der sächsischen Kulturpolitik aus demokratischer Verantwortung
}

\author{
Reiner Zimmermann
}

Die folgenden Ausführungen entnerungen an die rasanten Prozesse der Neuformierung der sächsischen Kulturlandschaft, in die ich als Leiter der Abteilung Kunst im Sächsischen Staatsministerium für Wissenschaft und Kunst verantwortlich eingebunden war. Herrn Prof. Dr. Hans Joachim Meyer, ehemaliger Staatsminister für Wissenschaft und Kunst, sowie Herrn Dr. Heinrich Douffet, dem damaligen Referatsleiter Museen und Denkmalpflege, danke ich für ihre Hinweise.

Staatsminister Prof. Dr. Hans Joachim Meyer und Dr. Reiner Zimmermann, 2001 Foto: G. Bartholomay sprechen meinen subjektiven Erin-

\section{Auftrag}

Mit der Entscheidung des ersten Kabinetts von Kurt Biedenkopf im Januar 1991, der sächsischen Kultur den gleichen Rang wie anderen Politikfeldern zuzubilligen, wurde dem Sächsischen Staatsministerium für Wissenschaft und Kunst (SMWK) die Verantwortung für die Bewahrung der aus der DDR überlieferten, teilweise überdimensionierten Kultureinrichtungen mit oftmals langer Tradition übergeben, zugleich war damit der Auftrag zu deren Bewertung und Weiterentwicklung eingeschlossen.

Für die großen staatlichen Kultureinrichtungen wie die Sächsische Staatsoper mit Staatskapelle Dresden, das Staatsschauspiel Dresden oder die Staatlichen Kunstsammlungen Dresden (SKD) sowie weitere große Museen in Dresden wie das Verkehrsmuseum, die Naturkundlichen Sammlungen, das Hygienemuseum und andere war nunmehr der Freistaat Sachsen zuständig. Zugleich musste in Zusammenarbeit mit den kommunalen Trägern der Fortbestand größerer kommunaler Kultureinrichtungen, an de-

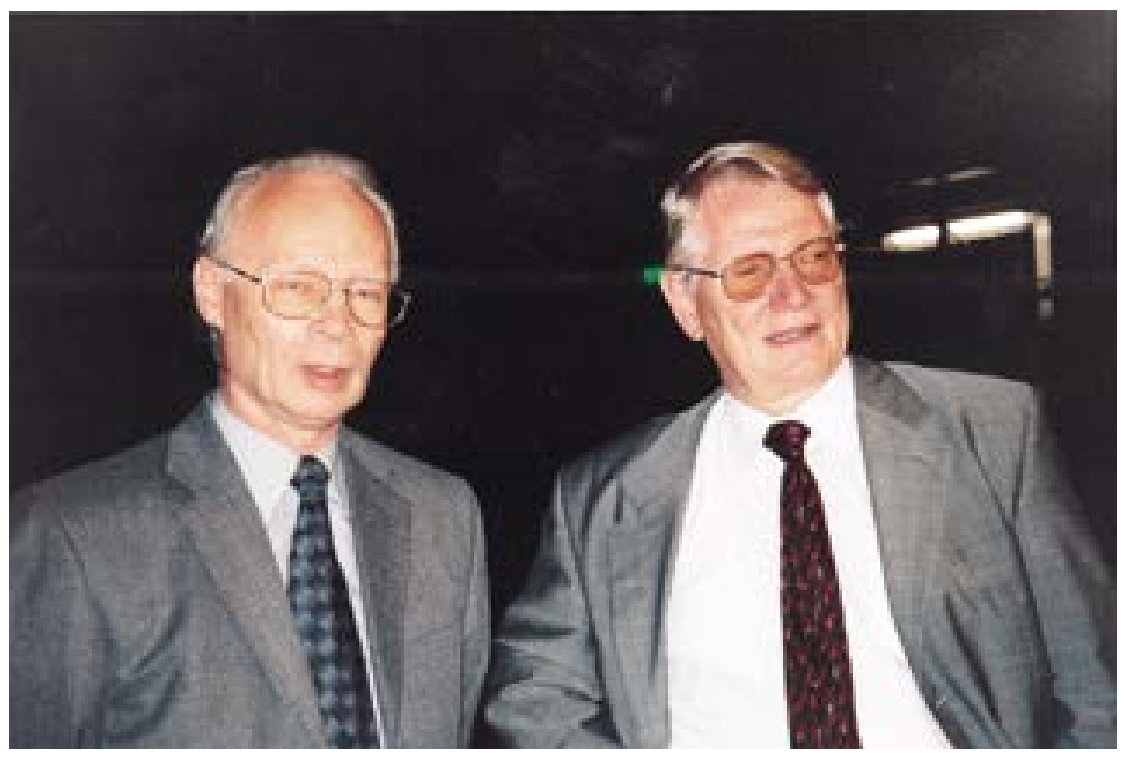

nen Sachsen so reich ist, ermöglicht werden. Das ergab sich daraus, dass in Sachsen seit Jahrhunderten nicht nur die höfische Kultur in Dresden, sondern durch die wirtschaftliche Entwicklung Sachsens seit dem 12. Jahrhundert auch die städtische Kultur sowie die des ländlichen Raums von hoher Qualität war, verbunden mit einem entsprechendem Selbstbewusstsein der künstlerisch Tätigen und der zahlenden Bürger.

Für die Leistungsfähigkeit sächsischer Kultureinrichtungen sei nur ein markantes Beispiel genannt: Zum Bachjahr 2000 plante der Sächsische Musikrat gemeinsam mit Kirchen, Musikhochschulen, Musikschulen, Laien-Ensembles und professionellen Musikern an jedem Sonnund Feiertag vom 1. Januar bis zum 31. Dezember in irgendeiner sächsischen Kirche die Aufführung einer der über 200 Kirchenkantaten von Johann Sebastian Bach. Welches deutsche Land sonst kann auf eine solche Breite künstlerischer Leistungsfähigkeit, basierend auf jahrhundertelanger Tradition, bauen? Diese Vielfalt galt es zu erhalten!

Die anfangs sehr bescheiden besetzte Abteilung Kunst des SMWK, in der wir immer vertrauensvoll zusammenarbeiteten, sah sich einer Fülle von Aufgaben gegenüber, die am liebsten alle auf einmal zu lösen waren. Zunächst standen Strukturüberlegungen im Vordergrund:

- die finanzielle Versorgung der staatlichen Kultureinrichtungen (hier muss daran erinnert werden, dass 1991 keine der Einrichtungen einen vom Parlament beschlossenen Haushalt hatte. Es gab nur sporadische Abschlagszahlungen. Das Gleiche galt für die kommunalen Einrichtungen.)

- die Umsetzung der beiden Bundesprogramme, des Substanzerhaltungsprogramms für größere kommunale Kultureinrichtungen sowie des Infrastrukturprogramms zur Finanzierung von ca. 800 kleineren kommunalen Projekten wie Unterstützung von Fahrbiblio- 
theken, Sicherungsmaßnahmen für kleinere kommunale Museen u.v.a.m., korrekt bearbeitet von unserem Haushaltsreferat, Frau Heide Gneipel und Bernd Angrik aus Baden-Württemberg, der für einige Jahre freiwillig zu uns kam und eine große Hilfe war. (Hierfür hatte das Bundesinnenministerium nach $₫ 35,7$ des Einigungsvertrages und unter argwöhnischen Blicken der alten Länder ein einigungsbedingtes Sonderprogramm zur Hilfe für die ostdeutschen Länder eingerichtet. Die 42,3 Prozent der Bundesmittel, die Sachsen aufgrund seiner kulturellen Dichte erhielt, mussten schleunigst unter die Einrichtungen verteilt werden. Diese Mittel zahlte der Bund von 1991 bis 1993, und für 1994 gab es dann noch die Hälfte der bisherigen Summe.)

- die Überprüfung aller Mitarbeiter des öffentlichen Dienstes auf belastende Kontakte zum Ministerium für Staatssicherheit der DDR mit entsprechenden Konsequenzen

- die Entscheidung über die Existenz vieler ehemals bezirksgeleiteter Kulturbüros und gegebenenfalls deren Überleitung in neue staatliche Stellen wie den Kunstfonds des Freistaates Sachsen, der die vom ehemaligen Rat des Bezirkes geförderte Bildende Kunst sammelte, oder die Sächsische Landesstelle für das $\mathrm{Mu}$ seumswesen, die kommunale Museen oder in privater Rechtsträgerschaft befindliche Einrichtungen wissenschaftlich beriet

- die Begleitung von kommunalen Entscheidungen über die Existenz von Kultureinrichtungen

- die Unterstützung bürgerschaftlichen Engagements zur Gründung von Vereinen und Landesverbänden

- die Einrichtung beratender Gremien wie Sächsischer Kultursenat, Sächsische Akademie der Künste, Kulturstiftung des Freistaates Sachsen und andere

- die Einbeziehung der künstlerischen Hochschulen - hierfür war Dr. Tatjana Frey verantwortlich - in den allgemeinen Erneuerungsprozess aller sächsischen Hochschulen, den das Ministerium mit Hochdruck vorantrieb.

Dass die Arbeit der Abteilung Kunst in das parlamentarische System des Freistaates und in das föderale System der Bundesrepublik Deutschland mit ihren Gremien und ihren Verfahrensvorgängen einbezogen war, versteht sich von selbst, brachte zugleich viele Aufgaben mit sich: die Beantwortung parlamentarischer Anfragen, die inhaltliche Vorbereitung von Kabinettssitzungen, von Minister-, Staatssekretärs- und Abteilungsleiterrunden innerhalb der Ständigen Konferenz der Kultusminister der Länder und vieler anderer Gremien, welches zum Alltag der Staatsbürokratie gehören.
Dass aber diese Staatsbürokratie eine Aufgabe nicht bediente, das unterschied sie von den vorangegangenen DDR-Behörden: Sie enthielt sich jeglicher inhaltlicher Einflussnahme auf die ihr zugeordneten Einrichtungen. Das erleichterte die Arbeit ungemein und schuf erstmals Vertrauen zwischen Kulturschaffenden und Verwaltung: ein hohes Gut eines demokratisch verfassten Gemeinwesens, das durch Arroganz und Ignoranz der Behörden rasch verspielt werden kann. Da diese täglichen Aufgaben alles andere als spektakulär waren, wurden wir zwar von Abgeordneten der Opposition des Sächsischen Landtags als unfähiges und inkompetentes Ministerium apostrophiert, aber die Abteilung Kunst sah ihre Aufgabe vornehmlich darin, die Voraussetzungen für ein florierendes Kulturleben zu schaffen, zum Beispiel durch Schwerpunktsetzungen in der Kulturförderung.

\section{Orchester- und Theatertradition}

Einer besonderen Herausforderungen sahen sich viele Kommunen und Landkreise durch die Vielzahl der Orchester und Theater gestellt. Auf damals 4,5 Millionen Einwohner in Sachsen kamen 21 Orchester einschließlich Theaterorchester und 13 Mehrspartentheater (im Vergleich dazu hatte Frankreich damals 18 Theater oder Italien 12 Theater) sowie - nicht $\mathrm{zu}$ vergessen - über 300 Museen. Statistisch gesehen gab es auf einer Strecke von $300 \mathrm{~km}$ zwischen Görlitz bis Plauen alle $15 \mathrm{~km}$ ein Orchester. Wenn diese, wie ich auswärtigen Journalisten erläuterte, bei den Proben laut spielten, könnten sie einander hören.

Und alle schauten nun hilfesuchend auf das SMWK und das Theaterreferat von Frigga Schnakenburg. Zwar gab es in Baden-Württemberg eine Regelung, nach der das Land 40 Prozent und der Träger 60 Prozent der anfallenden Kosten für Theater und Orchester übernahm, aber diese Mittel hatte der Freistaat 1991 nicht, da er zunächst selbst von der Gemeinschaft der alten Länder und des Bundes alimentiert wurde. Es war klar, dass die Kommunen und Landkreise die finanziellen Belastungen für all ihre Kultureinrichtungen nicht allein tragen konnten, zumal die Übergangsfinanzierung des Bundes für die ostdeutsche Kultur 1994 definitiv auslaufen sollte. So war es daher ein glücklicher Umstand, dass sich auf der Suche nach Lösungswegen für dieses gravierende Problem 1991 Dr. Matthias Theodor Vogt bei uns vorstellte, ein Musiker, Regisseur und Theaterwissenschaftler von universeller Denkungsart. Er hatte zunächst die Idee, eine „Clea- 


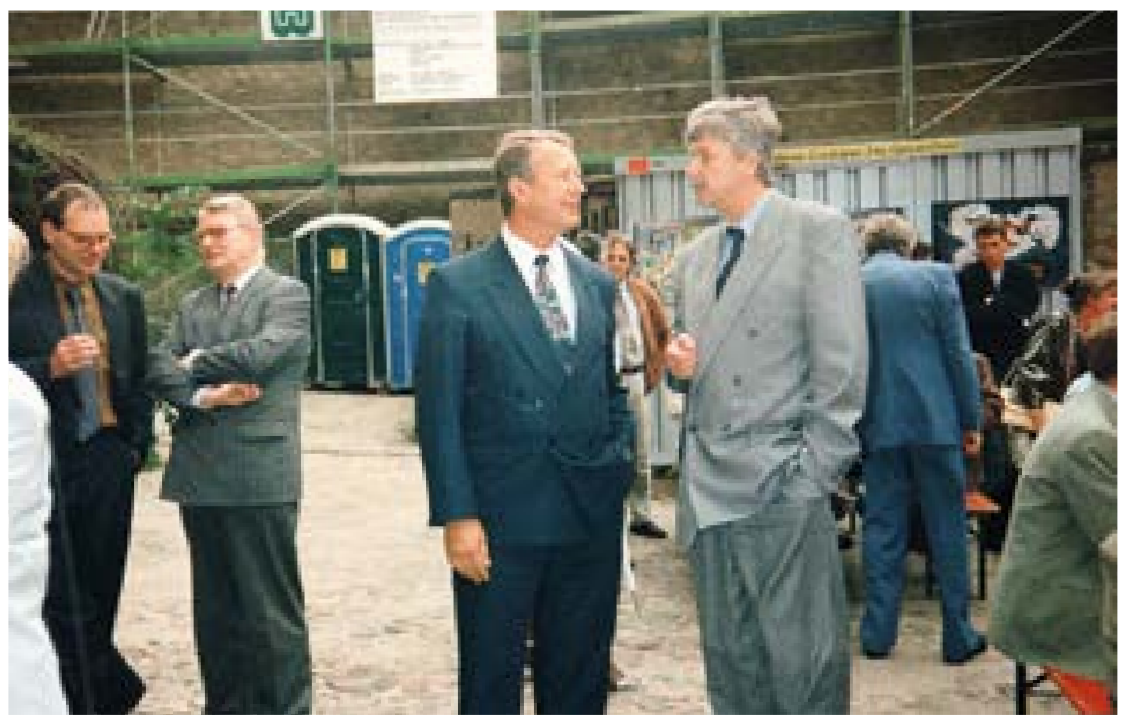

Gründung der Kulturräume auf Schloss Rochsburg, im Vordergrund rechts

Dr. Günther Beick, 12. Juni 1993 (C) Reiner Zimmermann
Karte der Kulturräume des Freistaats Sachsen, Stand 2015 ringstelle“, eine Art Treuhand für Kultureinrichtungen, einzurichten. Im Ergebnis seiner Bemühungen konnte schließlich die eigens gegründete "Naumann-Kommission“ 1993 einen perspektivisch bedeutungsvollen, zunächst heftig umstrittenen Bericht über die Theater und Orchester im Freistaat mit entsprechenden Empfehlungen für Umstrukturierungen vorlegen. Sie war nach dem sächsischen Hofkapellmeister Johann Gottlieb Naumann (1741-1801) benannt, der die Dresdner Hofmusik nach dem Siebenjährigen Krieg im Sinne des Rétablissements reorganisierte und dies danach in Stockholm und Kopenhagen wiederholte. Daraus ergab sich dann der Auftrag, eine gesetzliche Vorlage zur Sicherung größerer kommunaler Kultureinrichtungen über Theater und Orchester hinaus zu erarbeiten.

In einem landesweiten, teils kontrovers geführten Prozess unter Einbeziehung des Sächsischen
Landtages, des Kultursenats, der beiden kommunalen Spitzenverbände, der Bürgermeister und Landräte sowie der Künstler wurde am 17. Dezember 1993 ein in der Bundesrepublik Deutschland einmaliges Gesetz, das Kulturraumgesetz, über die Beteiligung eines Staates an der Finanzierung der kommunalen Kultur beschlossen, das zunächst befristet für eine Übergangsperiode gelten sollte, ab 2008 aber verstetigt wurde. Darin verpflichtete sich der Freistaat, etwa ein Drittel der anfallenden Kosten für die bestehenden Kultureinrichtungen $\mathrm{zu}$ übernehmen (1995 waren das 150 Millionen DM), das zweite Drittel wurde von den Rechtsträgern, das dritte Drittel aber von allen Kreisen der sogenannten Kulturräume als solidarische Kulturumlage geleistet. Die Kreise und kreisfreien Städte außer Dresden und Leipzig wurden in kulturellen Zweckverbänden zusammengefasst, die als Kulturräume bezeichnet wurden und etwa den früheren sächsischen Kirchenbezirken entsprachen, also damals auf regionale Besonderheiten Rücksicht nahmen.

So wie 1991 der Bund die besondere Lage der ostdeutschen Länder durch die Übergangsfinanzierung bis 1994 anerkannte, so fand sich der Freistaat Sachsen ab 1995 bereit, die außergewöhnlichen Belastungen der Kreise und Städte durch die vielfältigen kulturellen Angebote, die teilweise von überörtlicher Bedeutung sind, nicht durch Abwicklung, sondern durch Mithilfe $\mathrm{zu}$ fördern und qualitativ zu verbessern. Der Referatsleiter Dr. Günther Beick erwies sich als ein besonders findiger Helfer in allen Belangen der Kulturraumfinanzierung.

Einerseits sollte also dieses Kulturraumgesetz zu einer Stabilisierung der Finanzlage beitragen,

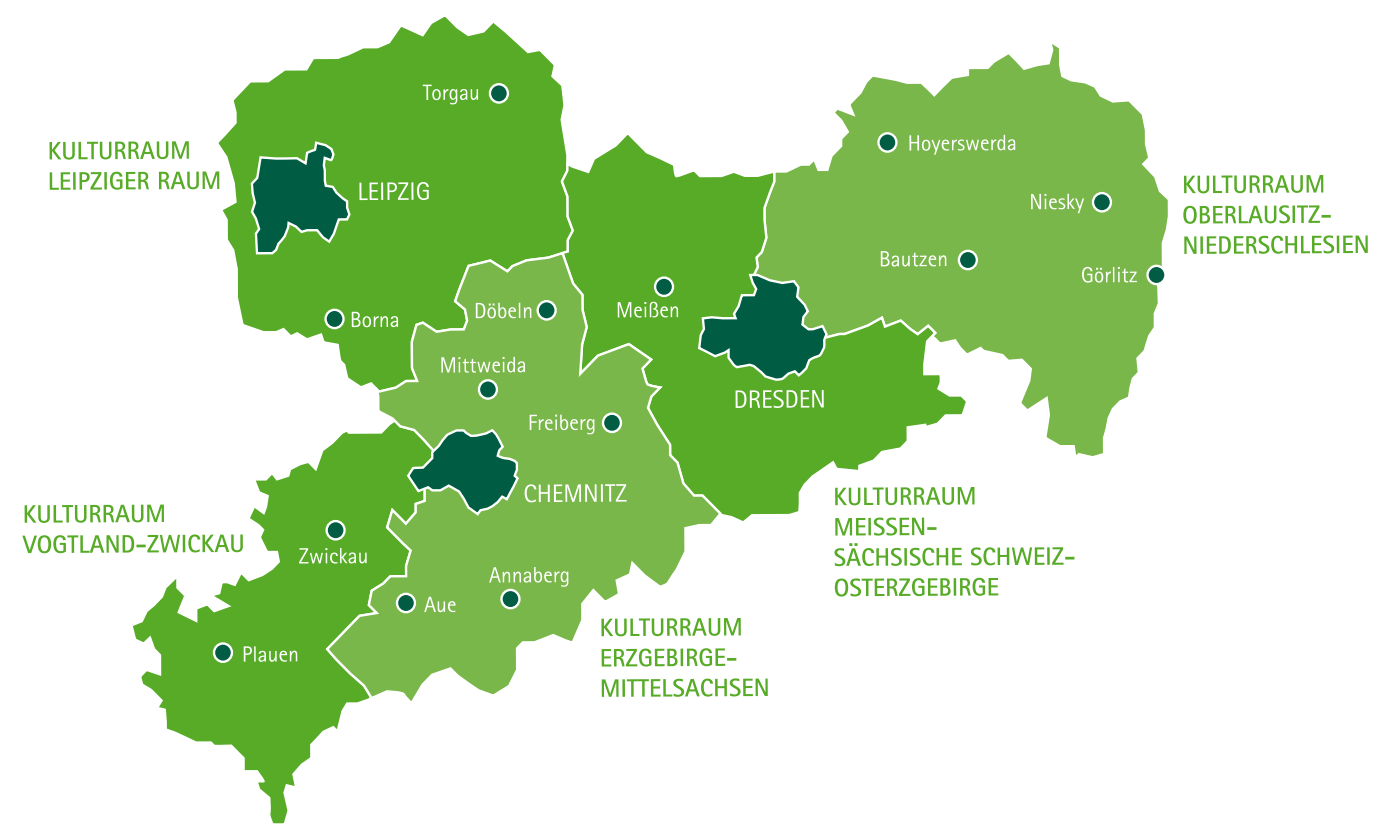


andererseits gab es einen gesetzlich verankerten Auftrag, Strukturen durch Evaluation zu überprüfen und zu hinterfragen. Das erforderte auch die vom Sächsischen Staatsministerium der Finanzen (SMF) ständig vorgebrachten Mahnungen zur Kosteneinsparung, denn die Einnahmen des Freistaates und der Kommunen wuchsen nicht im Verhältnis zu den erforderlichen Ausgaben. Verantwortliche Kulturpolitik stand daher immer im Spagat zwischen Bewahrung der kulturellen Vielfalt und den vorhandenen Finanzmitteln. In diesem Sinne war es notwendig, Theater- oder Orchesterverbünde zu schaffen, wobei es auch zur Auflösung von Einrichtungen kam. So führte zum Beispiel die Fusion des Theaters in Döbeln mit dem Theater in Freiberg zu einer Veränderung des Personalbestands, der einerseits in Verringerung des Personals in bestimmten Sparten, andererseits auch zu Aufstockungen führte. So blieb die Anzahl der Spielstätten und damit das kulturelle Angebot erhalten. Solche Entscheidungsprozesse wurden stets von der Abteilung Kunst begleitet, weil es das Ministerium als Verpflichtung ansah, die Kommunen und Kreise mit ihren Entscheidungen nicht allein $\mathrm{zu}$ lassen, sie gegebenenfalls finanziell zu unterstützen sowie strukturelle Entscheidungen mitzutragen.

Während der Arbeit an den Grundlagen des Gesetzes gab es in Sachsen eine landesweite Diskussion über Kunst im Freistaat, über deren Bedingungen und Wirkungen. Das führte $\mathrm{zu}$ einem größeren Verständnis vieler politischer Verantwortungsträger für kulturelle Leistungen und deren Voraussetzungen. Das Kulturraumgesetz schuf in diesem Sinne auch eine Grundlage für eine Beteiligung der Kulturschaffenden selbst an Entscheidungsprozessen über die jährliche Förderung der Einrichtungen und Projekte. Jede Kunstsparte wie Theater, Museen, soziokulturelle Einrichtungen und andere in einem Kulturraum entsandte Vertreter in den Kulturbeirat, der den politisch Verantwortlichen im Kulturraum, den Landräten und Bürgermeistern, eine zuvor diskutierte Förderliste übergab. Dadurch sind in Sachsen allein in den Kulturräumen etwa 800 Personen mit fachlicher Qualifikation an den Entscheidungen beteiligt.

Die Kulturpflege in Sachsen erschöpfte sich indessen nicht mit den durch das Kulturraumgesetz gesicherten Institutionen. Seit 1990 konnten sich Vereine und Verbände nunmehr entfalten, ohne politisch-ideologisch gegängelt zu werden. Sie waren aber auf öffentliche Zuwendungen nach wie vor angewiesen. Mit Hilfe eines Haushaltstitels, der Allgemeinen Kunst- und Kulturförderung, versuchte die Abteilung Kunst diesen rasanten Prozess der Eigeninitiativen zu unter-

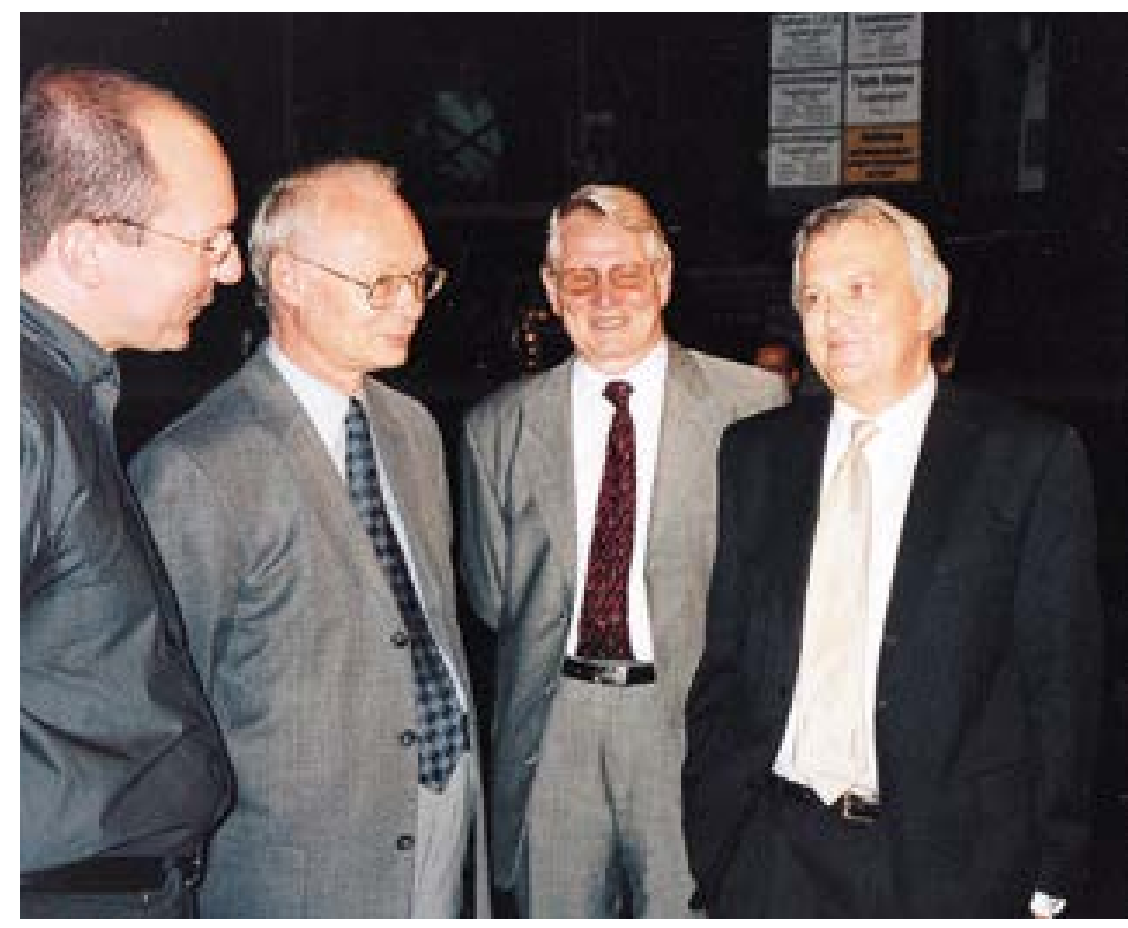

stützen, und zwar immer nach dem Subsidiaritätsprinzip. Der Freistaat finanzierte also nie ausschließlich und allein, sondern bestand darauf, dass mindestens ein weiterer Partner an der Finanzierung beteiligt sein musste. So bildeten sich die Landesverbände wie der Sächsische Musikrat, der Sächsische Filmverband, der Sächsische Literaturrat, der Sächsische Museumsbund, der Landesverband Soziokultur und andere. Wichtig für das Kulturland Sachsen waren auch angesehene Festivals wie das Bachfest Leipzig, die Chemnitzer Begegnungen, die Dresdner Musikfestspiele, das Zwickauer Schumann-Fest, die Silbermann-Tage in Freiberg oder das $\mathrm{Mu}$ sikfest Erzgebirge. Selbst im durch die Grenzlage zwischen Franken und Sachsen bislang völlig abgelegenen Winkel des Vogtlandes, in Mißlareuth, entwickelte sich ein Festival mit dem programmatischen Namen „Mitte Europa“. Es bleibt eine ständige Aufgabe der Festivalleitungen, sich um weitere Finanzierung zu bemühen, Firmen und andere Sponsoren zu gewinnen, was im Osten Deutschlands generell auf Probleme stößt. Zentralen großer Firmen liegen nun einmal nicht auf ostdeutschem Territorium, und andererseits waren genuin ostdeutsche Firmen im Anfang noch nicht solvent genug für großzügiges Sponsoring. Hier war und ist viel Fantasie gefragt, sollte ein anspruchsvolles Programm ohne wesentliche Abstriche präsentiert werden. Diese Zwänge führten dazu, dass sich die Findigkeit vieler Veranstalter freier Projekte erstaunlich gut entwickelte.

So zum Beispiel bei der Planung und Durchführung eines Festivals „Schalom Sachsen“, das
Spielzeitbeginn im Staatsschauspiel Dresden, von links Hergen Gräper, Staatsminister Prof. Dr. Hans Joachim Meyer, Dr. Reiner Zimmermann und Intendant Holk Freytag, 3. September 2001 Foto: G. Bartholomay 
jüdische Künstler einlud, mit Schwerpunkt in Chemnitz: Es gelang, kurzfristig das Gastspiel eines israelischen Ballettes in Zwickau als Abschlussveranstaltung zu organisieren. Ein weiterer Höhepunkt war der Auftritt des Wiener Chansonniers Georg Kreisler im Dresdner Theaterkahn am 12. März 1996, zumal dieser Künstler damals nur noch selten gastierte.

Die Chemnitzer Oper, 1992 im ansprechend modern sanierten Gebäude am Theaterplatz wiedereröffnet, behauptete ihren Rang neben Dresden und Leipzig sehr selbstbewusst unter anderem durch Aufführungen des „Ring des Nibelungen“ von Richard Wagner, die viele auswärtige Gäste, auch den Bayreuther Chef Wolfgang Wagner, anzogen. Für 2000 plante das Haus die deutsche Erstaufführung der biblischen Oper von Kurt Weill und Franz Werfel „Der Weg der Verheißung“, dessen Uraufführung 1933 in Berlin der Machtergreifung Hitlers zum Opfer gefallen war. Die Weill-Foundation in New York gab die Erlaubnis zur Aufführung, nur fehlte eine deutsche Bühnenfassung. Auf einer Sitzung des Verwaltungsrates des Deutschen Bühnenvereins in München brachte ich die Chemnitzer Theaterleitung mit dem Dramaturgen des Leipziger Gewandhausorchesters zusammen, woraus eine fruchtbare Kooperation entstand. Mit diesem Werk gastierte das Chemnitzer Opernhaus, unterstützt von der Abteilung Kunst, zur Weltausstellung 2000 in Hannover, in den USA und in Israel.

Die Chemnitzer hatten darüber hinaus den Vorzug und das Vergnügen, eines der letzten Gastspiele von Loriot $\mathrm{zu}$ erleben mit seiner Kurzfassung von Wagners „Ring“. Auch bei solchen besonderen Projekten kam ein Teil der Mittel vom SMWK, verantwortungsvoll einesetzt von Maria-Cornelia Ziesch und Evelin Däberitz.

\section{Weitere Förderinstrumente}

Mit der Gründung der Kulturstiftung des Freistaates Sachsen im Mai 1993, geleitet von Dr. Jürgen-Uwe Ohlau, wurde ein weiteres Instrument geschaffen, um Projekte in allen künstlerischen Bereichen zu unterstützen und Kooperationen mit anderen in der Bundesrepublik tätigen Stiftungen zu entwickeln. Zunächst erhielt die Kulturstiftung Zuschüsse vom Freistaat, bis 1995 durch den Ausstieg Sachsens aus der nach 1990 gebildeten ostdeutschen Stiftung Kulturfonds, dem Überbleibsel der Mittel aus der DDR-Kulturabgabe auf jede Kinokarte, Schallplatte und anderes, ein Kapitalstock angelegt wurde, von dessen Zinsen die Projekte finanziert wurden. 2002 entschied der Minis- terpräsident, dass die Allgemeine Kunst- und Kulturförderung durch das SKMW beendet und der Kulturstiftung des Freistaates übergeben werden müsse, eine kulturpolitisch kurzschlüssige Entscheidung, da dem Ministerium die Möglichkeit genommen wurde, Schwerpunktbildungen in bestimmten Kunstsparten zu unterstützen. Die Kulturstiftung wirkt nunmehr in den Bereichen Bildende Kunst, Darstellende Kunst und Musik, Film, Literatur, Soziokultur sowie bei spartenübergreifenden Vorhaben. Sie vergibt Arbeits- und Aufenthaltsstipendien zur Förderung von Künstlern und künstlerischem Nachwuchs und finanziert Ankäufe von Kunstwerken und Musikinstrumenten.

Hier sei eine Kuriosität erwähnt: Dr. Ohlau gelang es, den Konzertflügel Clara Schumanns aus Privatbesitz für das Schumann-Haus in Zwickau zu erwerben. Auf dem 100-DM-Schein der Bundesbank war das Porträt von Clara Schumann graviert. Auf der Rückseite sah man diesen Flügel. Dazu meinte der damalige Zwickauer Oberbürgermeisters Eichhorn, dieser Geldschein sei eine „Fälschung“, weil der Flügel vier Pedale zeigte, während das Original in Zwickau nur mit drei Pedalen ausgestattet ist.

Das Prinzip „Rückgabe vor Entschädigung“ im Einigungsvertrag wirkte sich auch auf den Kunstbesitz aus. Alteigentümer verlangten ihre Kunstwerke zurück, welche nach 1945 auf meist verschlungenen Wegen in öffentliche Museen gelangt waren. Nur was tut ein Eigentümer mit Gemälden, unter ihnen einige aus dem 15. Jahrhundert, sollte er sie alle zurückerhalten? Er müsste wohl ein gesichertes Objekt finden mit Klimaanlage, gepanzerten Fenstern und Türen sowie einem Restaurator, der die Kunstwerke ständig im Blick hat: Für einen Privatmann ein unlösbares Problem. Andererseits bestand die Gefahr, dass der jahrhundertelang bewahrte Kulturbesitz einer Familie durch Verkäufe sich in ein Nichts auflöste und damit Erinnerungen verloren gingen. Daher wurden zwischen Eigentümern und Geldgebern (Finanzministerium, Kulturstiftung der Länder u.a.) nach Kompromissen bezüglich der Sammlung Speck von Sternburg gesucht und durch den Referatsleiter Henning Rengshausen ein Vertrag ausgehandelt, der den Ankauf besonders wertvoller Gemälde durch die öffentliche Hand vorsah und deren Erlös eine Art Abfindung für die Eigentümer bedeutete. In diesem Sinne vorbildlich war das Handeln des Freiherrn Speck von Sternburg, der die Entscheidung im Einverständnis mit seiner Familie fällte, die ca. 150 Gemälde umfassende Sammlung aus dem 19. Jahrhundert dem Leipziger Bilder-Museum als Dauerleihgabe in ihrer Gesamtheit zu über- 
lassen. Dies garantierte dem Museum den Erhalt eines prominenten Sammlungsteils und ermöglichte den Staatlichen Kunstsammlungen Dresden durch Ankauf die Komplettierung des Cranachschen Katharinenaltars.

Hier ist die Kulturstiftung der Länder als eine Einrichtung zu nennen, die Bund und Länder seit 1988 gemeinsam finanzierten. Sie half Museen und Bibliotheken, wenn national bedeutsame Kulturgüter Gefahr liefen, im Ausland versteigert zu werden. Als Grundlage dient die Liste national bedeutender Kulturgüter, auf die innerhalb kürzester Frist solche gefährdeten Kunstwerke gesetzt werden können. Allerdings entsteht dadurch die Verpflichtung, diese Werke hierzulande anzukaufen. Durch gemeinsame Anstrengungen des Bundes und des jeweiligen Sitzlandes war es bis 2005, als der Bund seine Mitwirkung beendete, gelungen, für die neuen Länder, z. B. für Sachsen-Anhalt, den Quedlinburger Domschatz zu erwerben. Und für Sachsen konnten unter anderem mehrere Autographe von Robert Schumann für das Schumann-Haus in Zwickau angekauft werden.

Inzwischen hat der Bund eine neue Kulturstiftung gegründet, die sich vorrangig der Förderung zeitgenössischer Projekte zuwendet. Sie rechnet bei Anträgen mit dem gleichen Subsidiaritätsprinzip, wie es in Sachsen üblich ist.

Auch das Haus Wettin beantragte die Rückgabe vieler Kunstwerke und Gegenstände, die 1945 enteignet worden waren, nachdem sich der frühere Freistaat Sachsen 1924 mit dem Haus Wettin im Rahmen der Fürstenabfindung geeinigt hatte. Die langen Verhandlungen führten schließlich zu einem Vertrag, der aus Rückgaben und und dem Verbleib von Dauerleihgaben bestand, in dessen Folge jedoch eine sorgfältige Überprüfung aller Bestände der SKD und anderer Museen auf ihre Provenienz im Rahmen eines vom Bund finanzierten „Daphne-Projekts“ notwendig wurde.

Es geht ja allgemein nicht nur um die Rückgabe von Kunstwerken ehemals jüdischer Eigentümer wie gegenwärtig bei der Sammlung Gurlitt, sondern durch die „Schlossbergung“ nach 1945, ein euphemistischer Ausdruck für die Plünderung von Adelssitzen und Enteignung großbürgerlicher Sammlungen, um den Nachweis der Rechtmäßigkeit von Kunstbesitz in öffentlicher Hand. Das ist ein weites Feld, doch steht es einem demokratisch verfassten Gemeinwesen wohl an, liebgewordene Besitzstände auf ihre Rechtmäßigkeit hin vorbehaltlos zu überprüfen. Leider war es nicht gelungen, das Haus Wettin davon zu überzeugen, Kunstschätze aus seinem Besitz dauerhaft in einer familiär geprägten Ausstellung in Sachsen zu präsentieren. Ganz im Gegensatz hierzu steht die Präsentation von Kunstbesitz der
Familien von Schönberg und anderer sächsischer Adelsfamilien im Schloss Nossen.

Das SMWK war auch in die komplizierten und langwierigen Verhandlungen mit Polen und Russland über die Rückführung von Kulturgut eingebunden, das im Gefolge des Zweiten Weltkriegs ausgelagert worden war. In Sachsen betrifft dies unter anderem Kunstbesitz aus den SKD oder große Bestände alter wissenschaftlicher Literatur aus den Besitz der Sächsischen Landesbibliothek. Es geht um eine schwierige Balance zwischen den berechtigten Ansprüchen der genannten Länder, die vom NS-Staat systematisch ausgeplündert wurden, und den Wünschen deutscher Einrichtungen nach die Rückführung ihres Kulturgutes. Inzwischen gibt es für die Verhandlungen mit Russland wegen der gegenwärtigen dunklen politischen Großwetterlage keine Aussicht auf baldige Lösungen.

Im Mai 2000 wies ich beim Eröffnungsvortrag auf dem Deutschen Museumstag in Cottbus darauf hin, dass Kultur der unverdächtigste Botschafter in zwischenstaatlichen Beziehungen sei. Als Land mit Grenzen zur Tschechischen Republik und zu Polen muss dem Freistaat an gutnachbarlichen Beziehungen gelegen sein. Deshalb wurde vom Kultusministerium ein deutschtschechisches Gymnasium eingerichtet und die Studienbedingungen für polnische und tschechische Studenten an sächsischen Hochschulen geregelt. Zudem forderte ich schon 1992 in Bonn vom Bundesinnenministerium eine Verlagerung des seit 1972 laufenden Zonenrandförderungsprogramms von der Mitte Deutschlands an die neue Ostgrenze. Folglich setzten sich die Länder Mecklenburg-Vorpommern, Brandenburg und Sachen gemeinsam mit Vertretern des Bundes mehrmals an einen Tisch, um die Struktur eines solchen Programms zu entwerfen. Keinesfalls sollte den Nachbarn, die nicht mit der Übernahme der DM rechnen konnten, ein Programm aufgedrängt werden. Es sollten gemeinsame Projekte erarbeitet werden. Leider waren die Verantwortlichen in Bonn nicht von der Notwendigkeit unserer Ideen zu überzeugen.

Etwas zugänglicher erwies sich der Bund, und hier der jeweilige Bundesinnenminister, bei der Förderung des sorbischen Volkes. Galten die Sorben in der DDR als Vorzeige-Minderheit, deren slawische Sprache eine Brücke der unverbrüchlichen Freundschaft mit den Völkern der Sowjetunion bildete, so oblag den Ländern Brandenburg (für die Niedersorben) und Sachsen (für die Sorben in der Oberlausitz) eine Förderung ohne ideologischen Hintergrund. Die Stiftung für das Sorbische Volk wird gemeinsam von den zwei Ländern und dem Bund 
finanziert und garantiert den Erhalt der sorbischen Sprache, des sorbischen Schriftguts und der Literatur, der sorbischen Einrichtungen und der sorbischen künstlerischen wie volkskundlichen Traditionen, aufmerksam begleitet vom Sorbenreferat des SMWK, geleitet von Stanislaw Brezan.

\section{Sanierung, Aus- und Neubau von Kulturbauten}

Anfang der 1990er Jahre gab es einzelne Initiativen, die ohne eine politische Vorgabe praktische Kulturpolitik im Grenzraum betrieben. Dazu gehört die „Europera“, ein Projekt des ersten Intendanten des Görlitzer Theaters nach 1991. Er lud die Bürger aus Zgorzelec, dem polnischen Teil von Görlitz, ins Theater ein, die in heimischer Währung bezahlen konnten. Mit diesem Geld mietete er Probenräume in Zgorzelec an. Es gab Konzertprojekte mit dem Theater in Liberec (Reichenberg), es gab die Junge Europera-Philharmonie, es gab die Dresdner Akademie für Alte Musik in der Europera, und es gab schließlich den Plan des Intendanten, das völlig verschlissene Görlitzer Theater aufzugeben und auf der Neiße eine Brücke mit aufgesetztem Theaterneubau zu errichten, ohne Rücksicht darauf, dass die aufsteigende Feuchtigkeit oder gar die wiederkehrenden Überschwemmungen einem solchen Haus sehr zusetzen würden. Diese Pläne wurden nicht realisiert, aber dafür wurde das Görlitzer Theater in mehrjähriger Tätigkeit gründlich saniert und als ein wahres Schmuckstück der Theaterbaukunst um 1850 wiedergewonnen. Welch ein Verlust, wenn man es aufgegeben hätte!

Eines Tages rief der Referatsleiter Dr. Ackermann aus dem BKM, also dem Büro des Beauftragten der Bundesregierung für Kultur und Medien, der im neuen Berliner Kanzleramt residierte, an und fragte mich, was ich von einem Bundesprogramm für Kulturbauten im Osten hielte, wonach der Bund die Hälfte der Kosten und der Rechtsträger die andere Hälfte trüge. Wir reagierten sehr rasch und legten tags darauf die „Liste 1 “ vor, der noch sechs weitere Jahreslisten folgten. Der Hintergrund war folgender: Das Finanzministerium wollte, da ihm die 150 Millionen DM als ausschließlich konsumptive Kosten für die Kulturraum-Einrichtungen $\mathrm{zu}$ viel waren, 25 Prozent der jährlichen Zuwendungen für investive Zwecke umwidmen. Das hätte die Träger dieser Einrichtungen in große Schwierigkeiten gebracht und über Nacht $\mathrm{zu}$ massenweisem Kulturabbau geführt. Die an sich richtige Idee des SMF, auch etwas für die zur DDR-Zeit meist nur mit Ausnahmegenehmigungen arbeitenden und verschlissenen Häuser zu tun, um Technik und Theaterräume, Probensäle, Museumsbauten zu sanieren, ließ sich nicht ohne Verluste aus den Kulturraum-Mitteln realisieren.

Da kam die Idee aus Berlin gerade recht. Meine Frage an einen Oberbürgermeister war stets: „Haben Sie Geld? Sie brauchen nur die Hälfte zu zahlen!“. Das wurde stets beifällig aufge-
König-Albert-Museum in Chemnitz Foto: wikimedia, Reinhard Höll

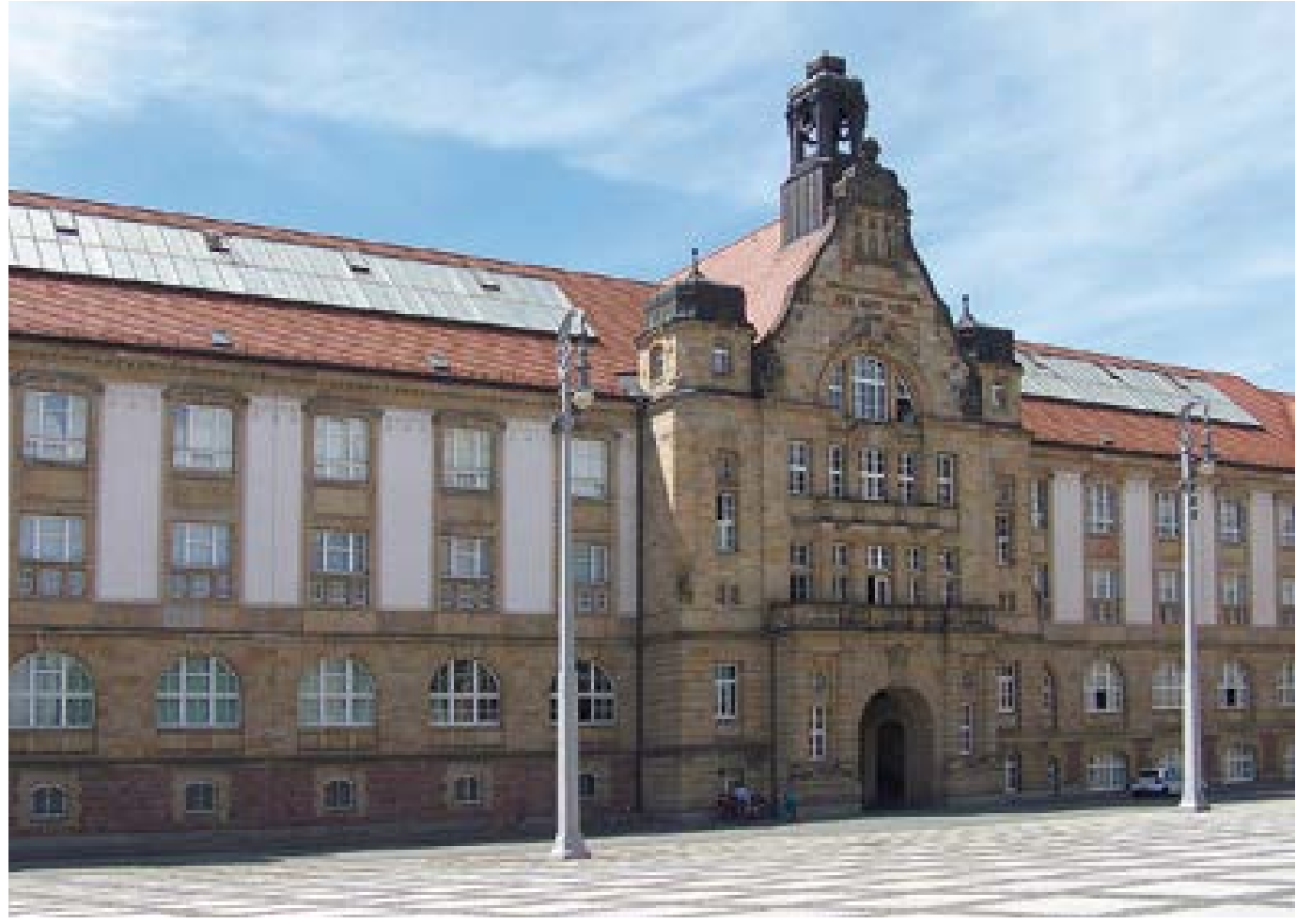




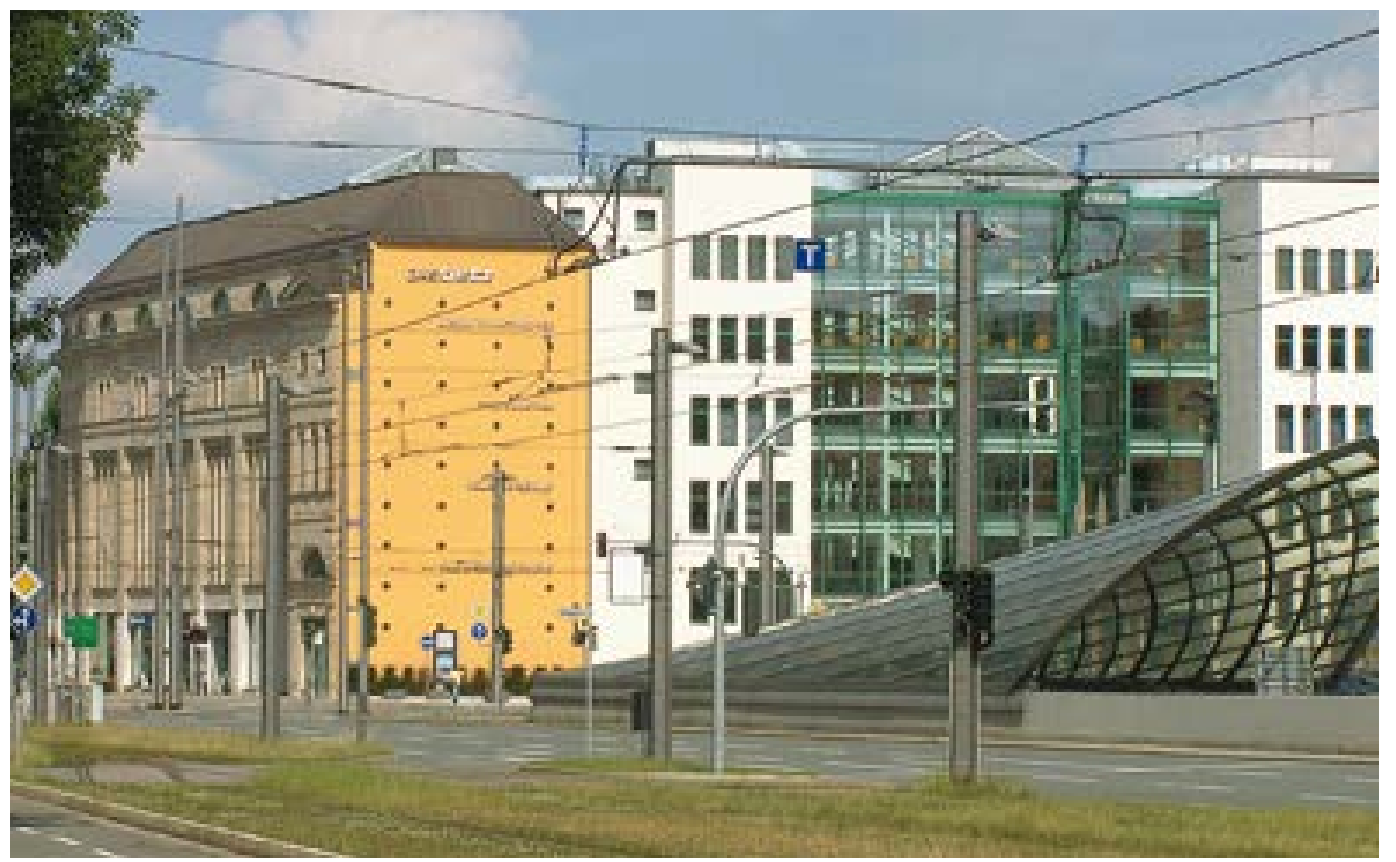

nommen. So wurde das König-Albert-Museum in Chemnitz endlich vollständig saniert, ferner wurde der Umzug der Naturkundlichen Sammlungen in das ehemalige Kaufhaus Tietz unterstützt. Und um den Standort Chemnitz als „Stadt der Moderne" auch seitens des Freistaates zu fördern, wurde das zentrale Museum des Verbundes „Sächsisches Industriemuseum“ dort errichtet und der Standort des neuen Archäologischen Landesmuseums bekräftigt. Das Robert-Schumann-Haus in Zwickau konnte modernisiert und auch das Görlitzer Theater von Grund auf saniert werden. Als man dort das Zuschauerparkett abtrug, sahen die Fachleute, dass es höchste Zeit war, hing doch das Parkett nur noch an einigen Fäden. Über 50 Baumaßnahmen, die auch der einheimischen Bauwirtschaft zugute kamen, sind später ohne Beanstandungen des Bundesrechnungshofes, der die Mittelausgabe überprüfte, korrekt abgerechnet worden.

Das Gleiche kann auch über die Mittel gesagt werden, die der Bund nach der Flut vom August 2002 bereitgestellt hatte. Unmittelbar nachdem die Scheitelwelle der Flut weitergeflossen war, nahmen wir die Schadensmeldungen, zumeist von kommunalen Einrichtungen, auf. Alles, was an Elbe und Weißeritz, an Mulde und Elster von brauner Flut durchnässt worden war, wurde mit ungefährer Kostenschätzung registriert. Manches Kulturgut ging indessen unwiederbringlich verloren. Am 16. August 2012 erhielten wir wiederum einen Anruf von Dr. Ackermann, der „eine Zahl“ brauchte für eine Besprechung im Bundeswirtschaftsministerium am selbigen Nachmittag, wo er ein Sonderprogramm Kultur herausschlagen wollte. Wir standen in den wenigen
Stunden unter erheblichem Druck, da die bisherigen vorläufigen und unvollständigen Schadensmeldungen noch keine vorzeigbare "Zahl“ ergaben. Aber dann erreichte uns die Schätzung des Staatshochbauamtes für die Semperoper und das Schauspielhaus, wo die Untermaschinerie 16 Meter unter Wasser stand, und das waren etwa 30 Millionen Euro. Wir meldeten mit diesen Hochrechnungen 56 Millionen Euro an, und das Sonderprogramm Kulturbauten wurde an diesem Tag mit 100 Millionen Euro bedacht, natürlich auch für Sachsen-Anhalt und weitere Anrainer nach Norden, weil dort die Elbe ebenfalls erhebliche Schäden angerichtet hatte.

Unabhängig von den Sanierungsmaßnahmen, die ab September 2002 notwendig wurden, hatte auch der Freistaat die Verpflichtung, seine Kulturbauten - ohne Bundeshilfe - zu sanieren. Die Semperoper bedurfte seit ihrer Eröffnung 1985 der jährlichen Wartung, wobei immer wieder auch technische Neuerungen eingebaut wurden. So stellte beispielsweise der Orchestergraben ein Problem dar: 1985 war er nach den Vorgaben der Denkmalpflege in den Maßen von 1871 wiedererstanden und nicht in der erweiterten Form, die Ernst von Schuch und Richard Strauss schon 1914 durchgesetzt hatten. Eine solche räumliche Beschränkung führte dazu, dass umfangreich besetzte Opern, zum Beispiel von Richard Strauss, nicht befriedigend aufgeführt werden konnten. (1985 kam man für „Elektra“ auf die Notlösung, das Orchester auf die Bühne und das Bühnengeschehen auf einen Sprungturm zu verlegen.) In den 1990er Jahren erhielt der Orchestergraben wieder seine für die moderne musikalische
Kulturkaufhaus DAS Tietz in Chemnitz

Foto: wikimedia, Reinhard Höll 
Konzertsaal der Hochschule für Musik in Dresden Foto: wikimedia, SchiDD
Praxis notwendige Größe, nachdem sich der neue Intendant Christoph Albrecht dies schon in seinem Vertrag vom August 1990, also vor Gründung des Freistaates, ausbedungen hatte. Sehr viel umfangreicher fiel die Sanierung des Schauspielhauses aus. Nach dem Wiederaufbau von 1948 mussten viele Nachkriegsprovisorien beseitigt und die denkmalgeschützte Untermaschinerie gründlichst überholt werden. Beim Zuschauerraum entschied sich das SMWK für eine Annäherung an die Gestaltung des Innenraums von 1911/13. Unerwarteterweise schwierig gestaltete sich das Problem der Bestuhlung, so dass manchem Zuschauer während der Eröffnungspremiere „Peer Gynt“ vor Spannung die Armlehne aus der Halterung fiel.

Im Kleinen Haus zeigten sich im Jahr 2000 Risse im Mauerwerk; es wurden Messpunkte angebracht, um den Fortgang zu kontrollieren, und es fiel die Entscheidung, das Haus hinter seiner Fassade neu $\mathrm{zu}$ errichten. Ich riet Intendant Prof. Görne, eine Ersatzspielstätte zu suchen. Er fand die künftige Schlosskapelle, und sie wurde mit Mitteln des Finanzministeriums kurzfristig als Schlosstheater eingerichtet, in dem eine Reihe bemerkenswerter Aufführungen von Schauspielen stattfinden konnten.

Währenddessen hatte die Musik- und Theaterhochschule in Leipzig hinter dem Hauptgebäude einen Konzertsaal-Neubau vom Freistaat erhalten. Dank einer Spendenaktion konnten Mittel für den Einbau einer zusätzlichen Bühne für studentische Aufführungen eingeworben werden. Das rief die beiden Dresdner Musikhochschulprofessoren Kluttig und Baumann auf den Plan. Sie wünschten sich einen ebensolchen Neubau einer Studiobühne. Damit konnte ich nicht dienen. Auch mein Hinweis auf das stets zurückhaltende Finanzministerium verfing nicht, das immerhin einer aufwändigen Sanierung des Hochschulgebäudes am Wettiner Platz sowie einem neuen Konzertsaal zugestimmt hatte. Bisher war die Hochschule mit ihren Inszenierungen ins Theater Meißen ausgewichen, zwar ein funktionierendes Haus, aber ohne technisches Personal von Studenten schwer zu bespielen. In einer Krisensitzung bei Minister Prof. Hans Joachim Meyer kam mir die Idee, noch während des laufenden Umbaus des Kleinen Hauses einen mobilen Graben für ein Studentenorchester einzubauen zu lassen, der bei Bedarf geöffnet werden konnte, hatte doch das Kleine Haus vor Eröffnung der Semperoper auch als Spielstätte für Kammeropern gedient. Ein Vertrag zwischen Hochschule und Intendanz sichert bis heute die sehenswerten studentischen Aufführungen, die dank eines funktionierenden technischen Hinterlandes stattfinden können.

Viel problematischer waren die Sanierungsarbeiten für die Staatlichen Kunstsammlungen Dresden und die anderen staatlichen Museen in Leipzig, Görlitz und Herrnhut. Das Finanzministerium war äußerst zurückhaltend bei der Finanzierung von Gebäuden, die zum Teil noch aus dem 19. Jahrhundert stammen. Lediglich der Semperbau der Galerie Alter Meister, den die Museumsmitarbeiter 1989 mit Rückendeckung der UNESCO hatten schließen lassen, um die DDR-Behörden zu dringend notwendi-

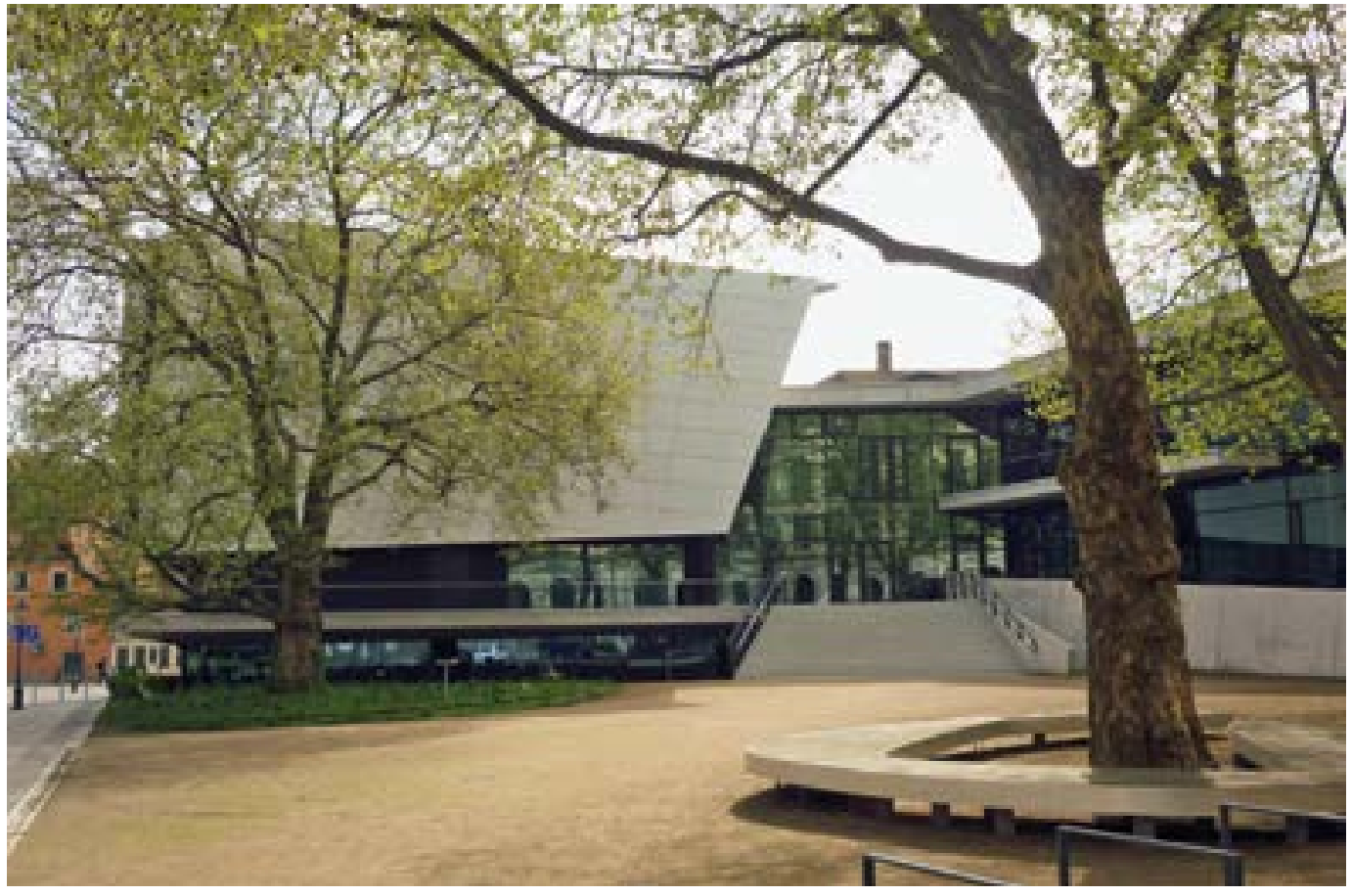




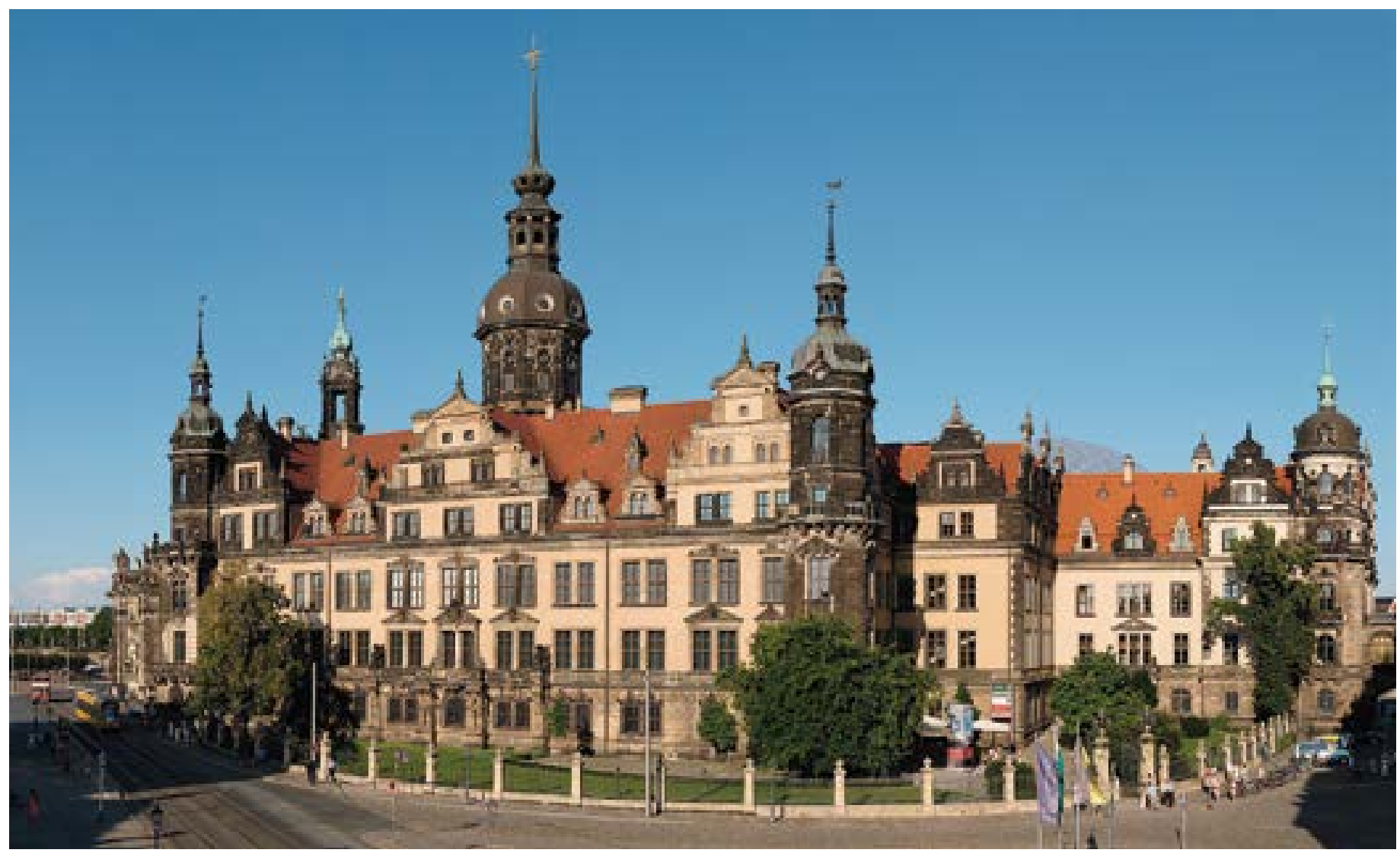

gen Baumaßnahmen zu zwingen, wurde 1992 wieder eröffnet. Momentan ist eine erneute Sanierung im Gange.

Der Wiederaufbau des Dresdner Residenzschlosses als Monument sächsischer Geschichte und Kultur war wohl der Schwerpunkt der Bautätigkeit des Finanzministers Georg Milbradt. Dieses Herzstück der Staatlichen Kunstsammlungen Dresden erforderte hohe Summen, so dass die Sanierung oder Erweiterung der Museumsbauten Gefahr lief, gänzlich gestrichen zu werden, von Neubauten gar nicht zu reden. Also musste das SMWK mit den SKD die Notwendigkeit von Sanierungsmaßnahmen nachweisen. Das geschah durch einige Museumskonzeptionen, in denen der Bedarf nach nationalen und internationalen Standards berechnet wurde. Die Haushälter des SMF rechneten immer mit und kamen ausnahmslos auf weniger Flächen als die Museen gerade belegten: eine nicht enden wollende Auseinandersetzung, die schließlich der damalige Finanzminister Thomas de Maizière 2002 beendete. Noch heute gibt es zum Beispiel für das Japanische Palais, ein Meisterwerk der Augusteischen Epoche, keine überzeugende Nutzung und infolgedessen keine Sanierung. Immerhin wurde damals das Kaufhaus Schocken in Chemnitz als Standort für ein Archäologisches Landesmuseums ins Gespräch gebracht. Nach jahrelanger Planung konnte es 2014 unter Beachtung modernster Erkenntnisse der musealen Präsentation und der Museumspädagogik eröffnet werden.

Für das Dresdner Residenzschloss gibt es eine gemeinsam von den Ministern Georg Milbradt und Hans Joachim Meyer eingebrachte Aufbaukonzeption, die das Kabinett 1997 beschloss. Vorausgegangen war eine umfangreiche Bestandsaufnahme und Überprüfung dieser Aufbaukonzeption des Landesamtes für Denkmalpflege, die durch ein internationales Gremium von Architekten, Museologen und Denkmalpflegern bestätigt wurde. Es ist zu hoffen, dass diese Konzeption weiter umgesetzt wird, denn das Dresdner Schloss ist ein einmaliges Ensemble von großer künstlerischer, architektonischer und geschichtlicher Tradition. Allein schon die Schlosskapelle mit dem wiedererstandenen Schlingrippengewölbe ist nicht nur ein sehenswerter musealer Ort, sondern war das Zentrum der evangelischen Kirchenmusik im 16. und 17. Jahrhundert, die von Dresden im Kurfürstentum Sachsen aus den Weg in die Welt nahm. Deren Geburtsort ist die Schlosskapelle auf Schloss Hartenstein in Torgau, der Wirkungsstätte des ersten protestantischen Kantors Johann Walter. Sie wurde im Zuge der 2. Sächsischen Landesausstellung saniert. Aller zwei Jahre wird auf meine Anre-
Das wiederaufgebaute Residenzschloss in Dresden, heute Museumsstandort der Staatlichen Kunstsammlungen Dresden

Foto: wikimedia 
Lange Schlangen bei der 1. Sächsischen Landesausstellung "Zeit und Ewigkeit" in St. Marienstern (C) Landesamt für Archäologie Sachsen gung hin hier die Johann-Walter-Plakette des Sächsischen Musikrates für herausragende Verdienste um das sächsische Musikleben verliehen.

\section{Landesausstellungen und Weltkulturerbe-Projekte}

Die Idee zu einer Landesausstellung nach österreichischem Vorbild als eine Art Leistungsschau einer Region hatte Finanzminister Georg Milbradt. Für die erste dieser Ausstellungen fiel die Wahl auf das Kloster St. Marienstern in Panschwitz-Kuckau, eines von zwei seit über 700 Jahren ununterbrochen bestehenden Zisterzienserinnenklöster in der Oberlausitz. Die Landesarchäologin Judith Oexle nahm die Sache in ihre organisatorisch strengen Hände, ließ auf dem Gelände des Klosters Gebäude sanieren, ebenso den Kreuzgang, der normalerweise nicht öffentlich zugänglich ist, und wertete den Standort für viele Besucher auf. Das Thema für die Dauer der Ausstellung von 128 Tagen lautete: „Zeit und Ewigkeit“. Bei den ansässigen Nonnen hieß das: 128 Tage sind eine lange Zeit, und es dauert eine Ewigkeit, bis sie vorüber sind. Die 2. Sächsische Landesausstellung 2004 „Glaube und Macht. Sachsen im
Europa der Reformation" wertete die ehemalige Residenz des ernestinischen Sachsens, das Schloss Hartenstein in Torgau, auf. Einige Flügel des Schlosses wurden für Ausstellungszwecke baulich und klimatisch hergerichtet, da kostbare Gemälde aus den SKD sowie weitere empfindliche Ausstellungsstücke gezeigt werden sollten und somit auch heute noch Ausstellungen möglich sind. Großen Wert legte Minister Prof. Hans Joachim Meyer auf die Sanierung des dortigen Wendelsteins, ein architektonisches Kleinod, das fürstliches Selbstbewusstsein demonstrierte. Er war dann zur Landesausstellung tatsächlich wieder begehbar.

Es war mir aufgefallen, dass bei der Vorbereitung der Landesausstellung in Torgau durch die SKD die Musik nicht einbezogen war. Nun ist die Torgauer Schlosskapelle zweifellos der wichtigste Ort für die frühe evangelische Kirchenmusik. Wir gründeten daher eine Arbeitsgruppe mit Prof. Wolfram Steudte, einem exzellenten Kenner der Musik der Renaissance, und der „Torgauer Ökumene“ - das waren der katholische Kantor und der evangelische Kirchenmusikdirektor. Und tatsächlich erhielt die Musik sogar eine Sonderzuweisung des Finanzministeriums für die Aufführungen eines auserwählten musikalischen Begleitprogramms.

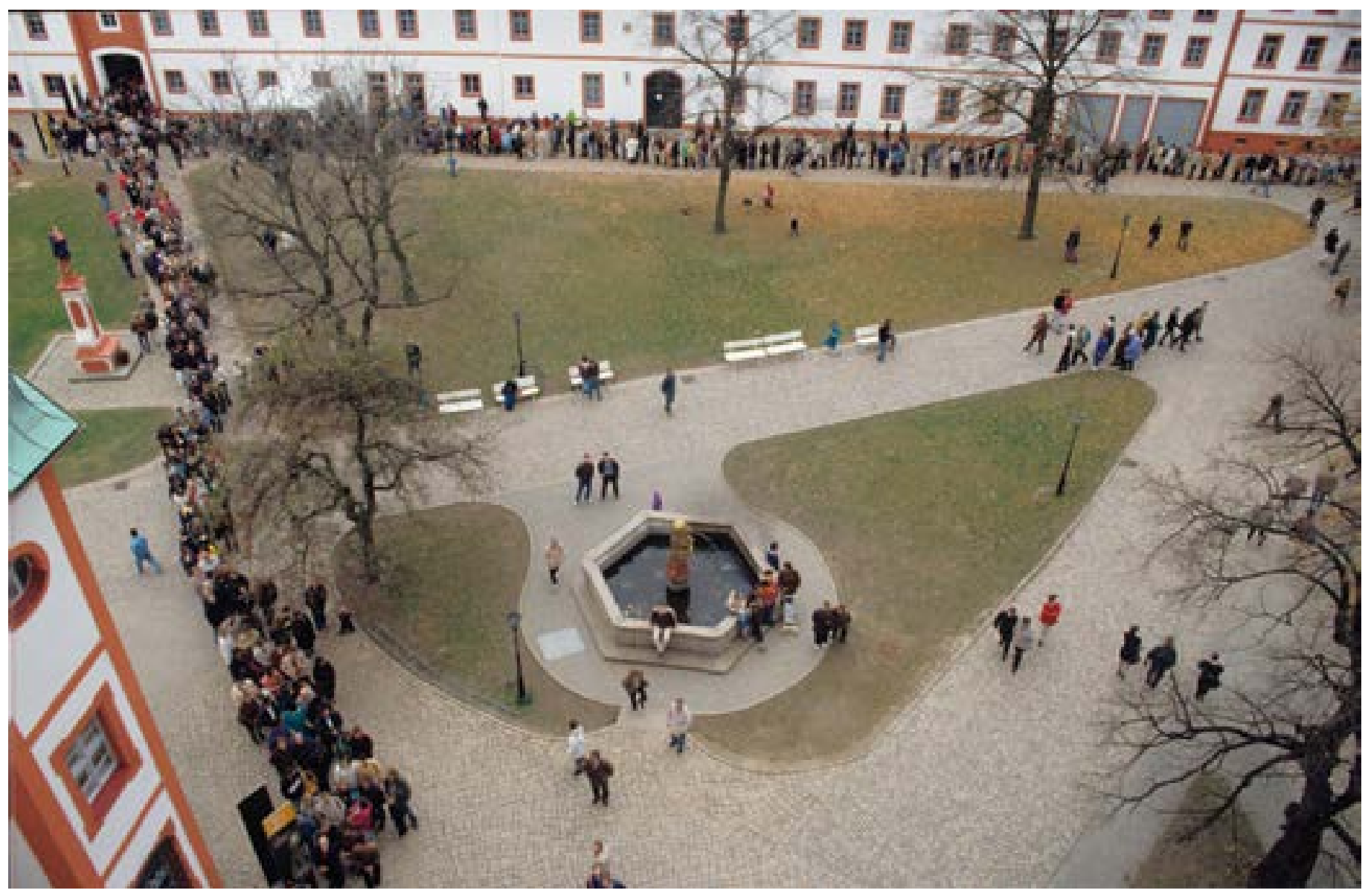


Die 3. Sächsische Landesausstellung im Kaisertrutz in Görlitz zeichnete die Wege der „via regia" nach, der wichtigen Handelsstraße von Ost nach West, deren Benutzer Görlitz im Mittelalter reich gemacht haben.

Görlitz hat aber noch andere Reichtümer: Die vom Zweiten Weltkrieg verschonte Stadt weist eine architektonische Fülle von Bauwerken der Renaissance über Barock bis zur Gründerzeit aus, die bis 1990 sträflich vernachlässigt wurden, obwohl die städtischen Denkmalpfleger schon zur DDR-Zeit sehr wohl den Reichtum der Stadt erkannten, aber mit den damals beschränkten Mitteln kaum den Verfall abwenden konnten. Nun wurde aus Görlitz eine der schönsten Städte Deutschlands, ermöglicht durch die Kombination vieler Förderprogramme und vieler Eigeninitiativen. Auch der Freistaat trug zur Verschönerung des Stadtbildes bei: Auf Anregung von Dr. Heinrich Douffet entstand am Untermarkt 4, im Schönhof und angrenzenden Gebäuden bis zum Fischmarkt, das Schlesische Museum zu Görlitz, getragen von einer Stiftung unter Mitwirkung des Bundes, des Freistaates, der Stadt Görlitz und der Landsmannschaft Schlesien. Die Dauerausstellung zeigt 1000 Jahre Geschichte Schlesiens, die eng mit Görlitz verbunden ist.

Die Planung solcher Vorhaben war ohne den hohen Fachverstand der Mitarbeiter des Landesamts für Denkmalpflege, das dem SMWK zugeordnet war, nicht vorstellbar. Ob Wiederaufbaukonzeption der Frauenkirche, zu der der Freistaat auch einen Beitrag leistete, ob Schlosskonzeption, ob Antrag Weltkulturerbe Dresd-

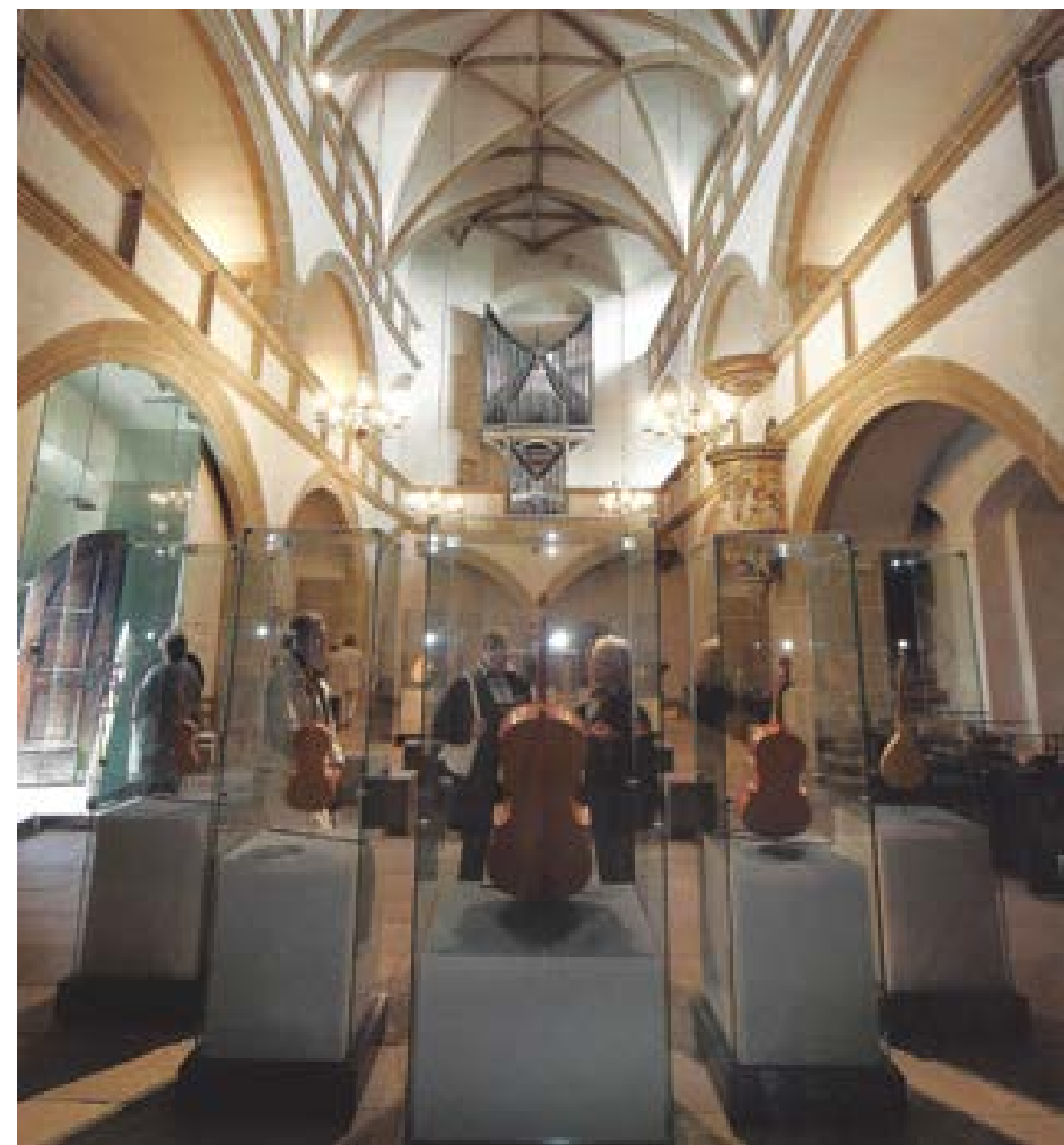

ner Elbtal, überall war die Handschrift von Hans Nadler, Heinrich Magirius, Gerhard Glaser und später Rosemarie Pohlack zu erkennen. Ohne diese Persönlichkeiten und deren Mitstreiter wäre vieles vom überkommenen oder
Die Torgauer Schlosskapelle als Teil der 2. Sächsischen Landesausstellung „Glaube und Macht" 2004

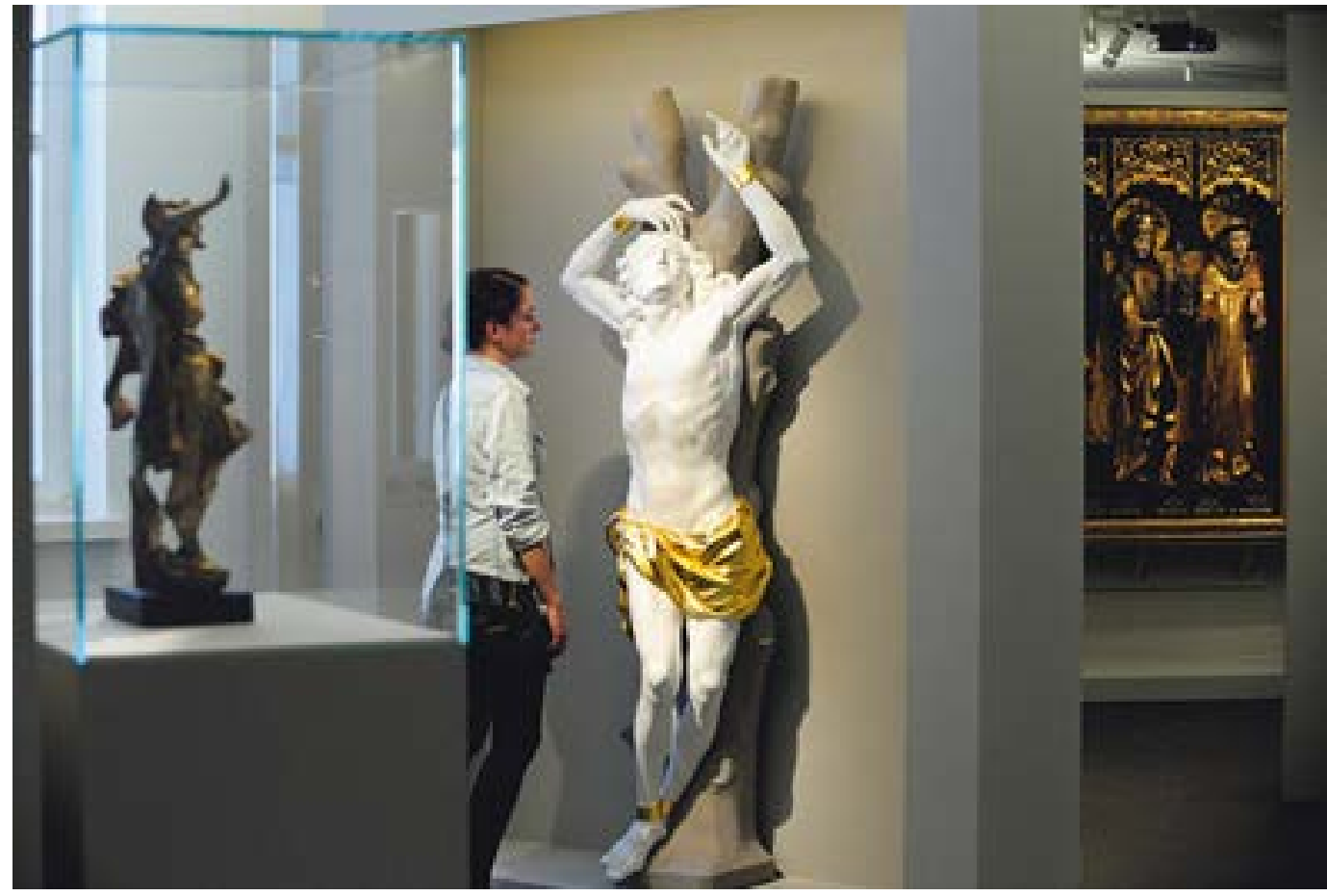

Ausstellungsraum der 3. Sächsischen Landesausstellung „Via regia - 800 Jahre Bewegung "und Begegnung" 2011 in Görlitz 


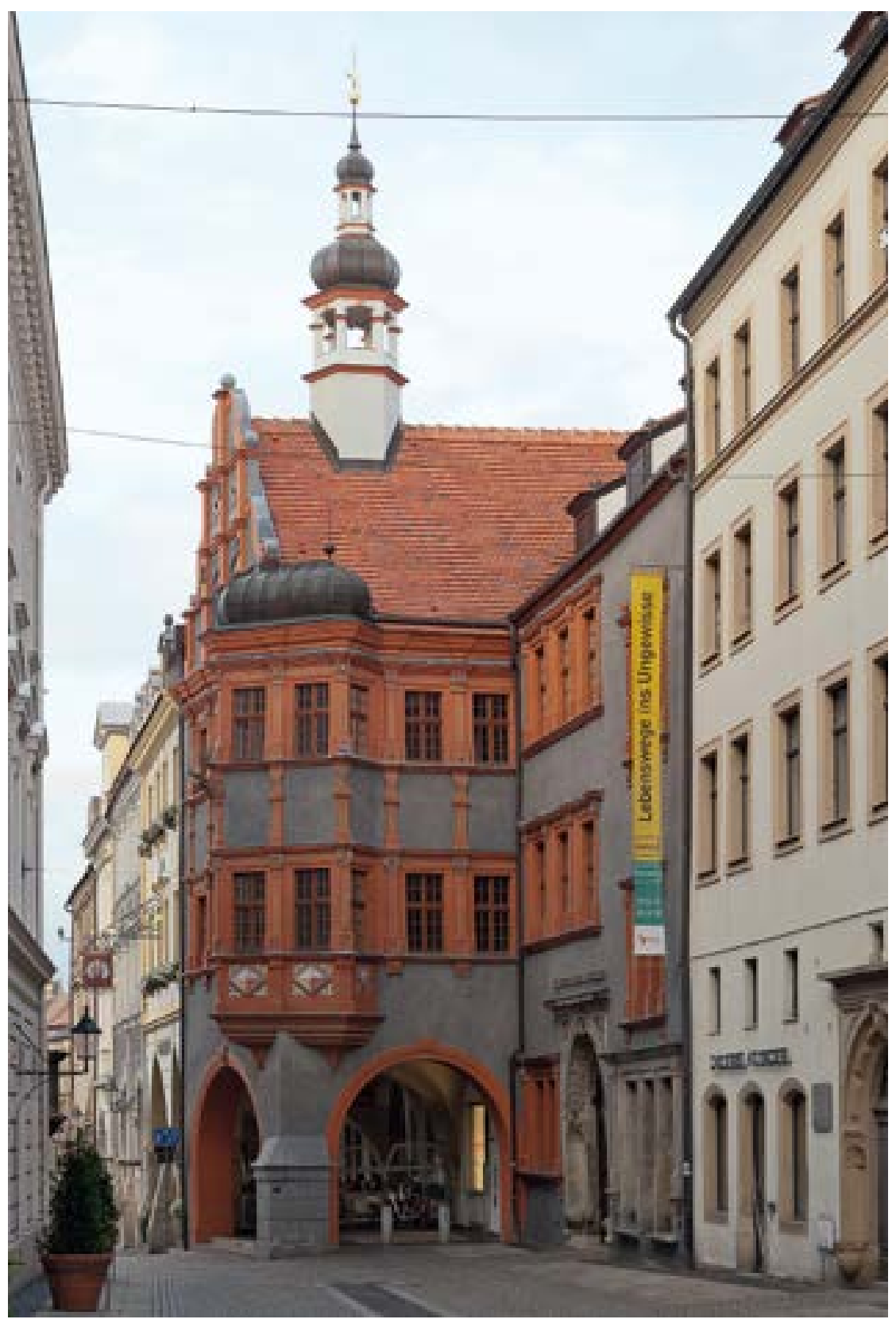

Der Schönhof in Görlitz, heute Schlesisches Museum Foto: wikimedia, Mylius zerstörten baulichen Erbe nicht rekonstruiert worden oder neu entstanden. Dank kollegialer Verbindung zum Referat Denkmalschutz im Innenministerium konnte auch ein vorbildliches sächsisches Denkmalschutzgesetz entstehen.

Was im Dresdner Elbtal misslang (wegen des Baus der Waldschlösschenbrücke wurde der ursprünglich genehmigte Status des Welterbes wieder aufgehoben), das gelang an der Grenze zu Polen mit dem Fürst-Pückler-Park in Bad Muskau, der als Weltkulturerbe den auf polnischer Seite gelegenen größeren Parkteil einschließt. Sogar das noch im April 1945 zerstörte Schloss ist inzwischen wieder aufgebaut worden. Ein weiteres Weltkulturerbe-Projekt, initiiert von Dr. Heinrich Douffet, liegt momentan den internationalen Gremien zu Entscheidung vor. Es handelt sich dabei um die „Montanregion Erzgebirge“, die die Grenzregion auf der tschechischen Seite einschließt.

Die Aufteilung in wissenschaftliche Belange des Denkmalschutzes mit der Anbindung des Landesamtes für Denkmalpflege an das SMWK sowie die Klärung juristischer und finanzieller Belange durch das Innenministerium hatte zur Folge, dass zwei Minister, von denen Prof. Hans Joachim Meyer für einige Jahre dem Deutschen Nationalkomitee Denkmalschutz vorstand, die Interessen des Denkmalschutzes im Kabinett vertraten - ein nicht unerheblicher Vorteil angesichts der verkommenen, aber förderungswürdigen Bausubstanz sächsischer Städte, Schlösser und Burgen. Anfangs war die Abteilung Kunst noch für die im Aufbau befindliche sächsische Schlösserverwaltung zuständig, die dann richtigerweise dem Finanzministerium als Träger staatlicher Liegenschaften zugewiesen wurde.

\section{Museen und Ausstellungsgebäude}

Schon 1992 einigten sich die Stadt Leipzig, der Freistaat und der Bund, das international bedeutendste Forschungsinstitut der Bachforschung, das Bach-Archiv, in eine Stiftung umzuwandeln, die für Forschung, Museum, Bachfeste und Bachwettbewerbe verantwortlich ist, und den in der DDR üblichen hohen Personalbestand zu reduzieren. Die Abteilung Kunst hat die Arbeit des Bach-Archivs stets angemessen unterstützt, da die Stadt Leipzig selbst große Anstrengungen unternahm, diesem Institut alle nötige Förderung zukommen zu lassen bis hin zum Aus- und Umbau des Bosehauses an der Thomaskirche $\mathrm{zu}$ einem modernen Bach-Museum.

Auch Einrichtungen aus dem Geschäftsbereich des SMWK wurden in Stiftungen umgewandelt. So das Deutsche Hygienemuseum in Dresden, dessen Domizil, der Wilhelm-Kreis-Bau von 1930, mit Bundeshilfe in den Jahren 2001 bis 2005 gründlich saniert wurde. Freistaat, Stadt Dresden und die DVK Deutsche Krankenversicherungen beteiligen sich an der laufenden Finanzierung.

Das Verkehrsmuseum Dresden hatte das SMWK aus der Konkursmasse des Ministeriums für Verkehr der DDR übernommen. Seine Unterbringung im Johanneum, dem ursprünglichen Stallgebäude der Dresdner Residenz mit Gewehrgalerie im Langen Gang, der nachmaligen Gemäldegalerie und Antikensammlung, der nachmaligen Porzellansammlung und dem späteren Historischen Museum ist für Fahrzeu- 


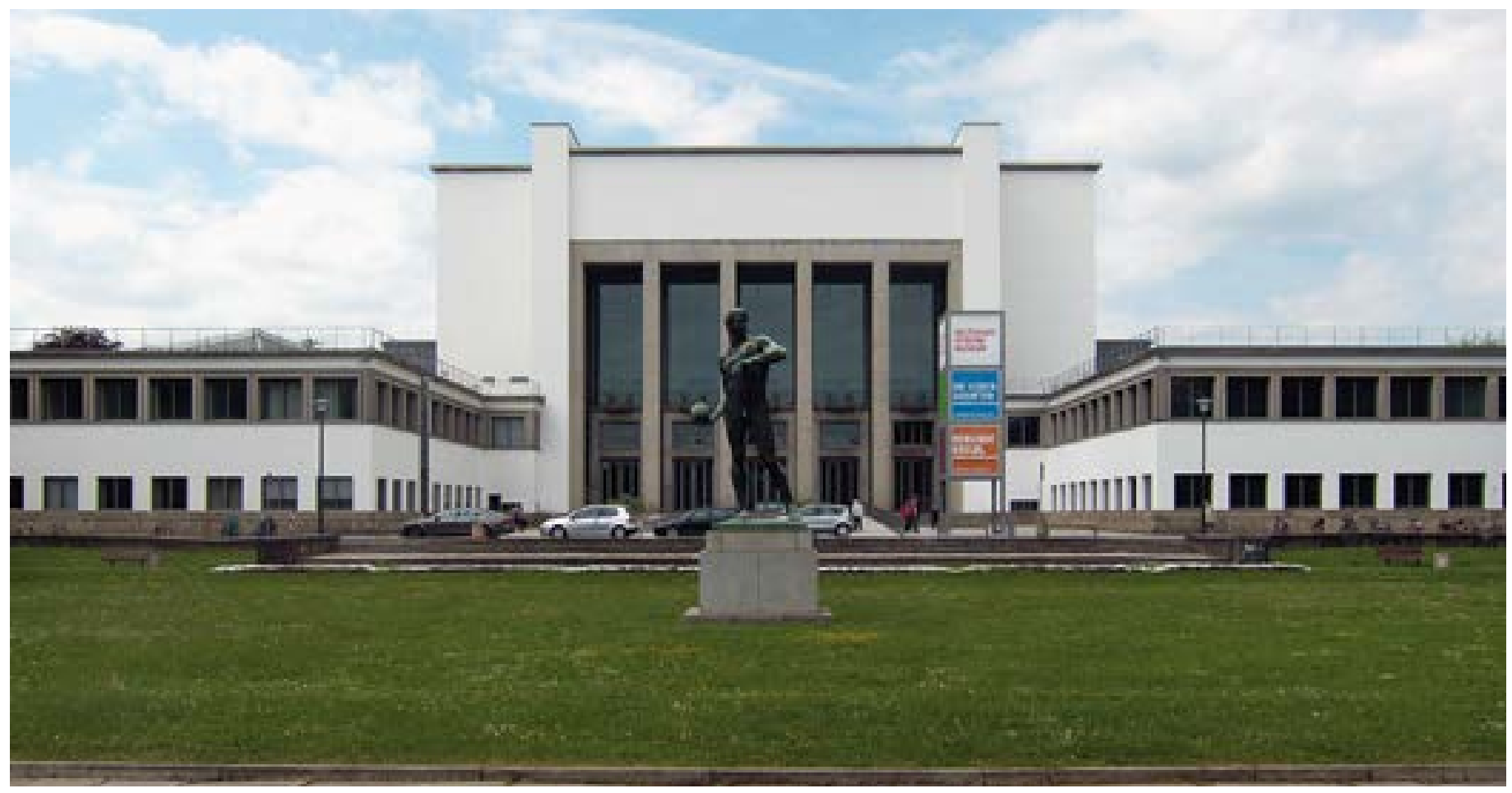

ge aller Art denkbar ungeeignet. Deshalb bemühten sich Dr. Heinrich Douffet und ich, den damaligen Staatsekretär Wolfgang Zeller vom Wirtschaftsministerium $\mathrm{zu}$ überzeugen, das Verkehrsmuseum auf einer ebenen großen Fläche unterzubringen, auf der Industriebrache des früheren Leipziger Bahnhofs, im Verlauf des Neustädter Bahnhofs Richtung Elbe gelegen: ein städtebaulich auszubauendes, zentral gelegenes Gelände, noch dazu mit historischer Bausubstanz der Bahnhofshalle von 1871 als Eingangssituation für das Museum. Welche Möglichkeiten hätten sich ergeben: überdachte Hallen mit Schienen für die Eisenbahnen, Plätzen für die Flugzeuge und Autos, alles ebenerdig und großzügig. Auch andere Standorte mit anderen Vorteilen hatten keine Chance; unsere Ideen waren offenbar nicht überzeugend genug. Bis heute gibt es keine annehmbare räumliche Lösung. Auch das lernt man: Nicht alle Ideen reifen.

Dagegen gelang es, die Naturkundlichen Sammlungen in Dresden, also das Museum für Tierkunde Dresden, das Museum für Mineralogie und Geologie Dresden, die Naturhistorische Zentralbibliothek sowie das Naturkundemuseum Görlitz in den Verband der der LeibnizGemeinschaft angehörenden Senckenberg Gesellschaft für Naturforschung zu integrieren. Sie wird vom Bund und den Ländern finanziert und versteht sich mehr als Forschungseinrichtung, weniger als museale Präsentationsform. Als die Studienstiftung des deutschen Volkes im Mai 2000 eine Ausstellung mit Werken ihrer Sti- pendiaten in Dresden anregte, fehlte ein geeigneter Ausstellungsraum. Wiederum kam unerwartet rasche Hilfe vom Finanzminister Georg Milbradt, der, einst selbst Stipendiat dieser Stiftung, das ruinöse Oktogon der Hochschule für Bildende Künste auf der Brühlschen Terrasse kurzfristig unter Beibehaltung der Narben, die der Krieg dem Gebäude zugefügt hatte, in ein ansehnliches Ausstellungsareal verwandeln ließ, das die Hochschule noch heute nutzt. Es zeigte sich immer wieder, dass es trotz der beständigen und verpflichtenden Aufgabe des Finanzministeriums, die Nettokreditaufnahme, also die Staatsverschuldung niedrig zu halten, um künftige Generationen nicht unmäßig zu belasten, zu beachtlichen Kompromissen mit einigen Kollegen des SMF kam, die dem kulturellen Aufbau Sachsens sehr zugute kamen. Dafür muss man dankbar sein, wenngleich wir damals häufig anderer Meinung waren.

Als um 2002 im Freiberger Dom die dem Freistaat zugehörige Begräbniskapelle der Wettiner mit dem Moritz-Monument restauriert wurde, nahm man auch die 16 Meter hoch gelegenen musizierenden Engel von ihren Podesten, um deren Instrumente im Musikinstrumentenmuseum der Universität Leipzig gründlich $\mathrm{zu}$ untersuchen. Es handelt sich nicht um ein spezielles Orchester, sondern um den gesamten Instrumentenbestand der weltlichen und geistlichen Musik, wie er am Dresdner Hof der Spätrenaissance verwendet wurde. Dabei stellten sich höchst überraschende Ergebnisse ein, denn teilweise waren originale Streich-Instru-
Deutsches Hygiene-Museum in Dresden

Foto: wikimedia 
mente eingebaut worden, die im späten 16 . Jahrhundert in der näheren Umgebung von Freiberg gebaut worden waren. Es genügte eine zehnminütige Beratung, um vom Abteilungsleiter Bau im Finanzministerium, Wolf-Karl Reidner, der uns immer gewogen war, weil er für den Kulturbereich so ansehnliche Bauten sanieren konnte, die Erlaubnis für eine Ausstellung der musizierenden Engel im Freiberger Stadtmuseum zu erwirken. Hier konnten die Besucher diese Figuren und Instrumente aus unmittelbarer Nähe betrachten, bevor sie wieder in die Höhe des Chorraumes entschwebten. Dank Spenden sind diese Instrumente nachgebaut worden und werden für Aufführungen der damaligen Musik verwendet.

\section{Umgang mit DDR-Kunstwerken}

Nach dem Ende der DDR fielen viele im Westen voller Häme über die Auftragskunst in der DDR her: Honecker auf Wildschweinleder war die Bestmarke. Dabei herrschte bei den Kritikern größte Unkenntnis, denn die Vergabe von Aufträgen an Künstler aller Sparten gehörte zum kulturpolitischen Konzept der DDR, wonach vorrangig Werke ideologischen Inhalts gefördert wurden. Dass daneben auch kritische oder qualitativ bemerkenswerte Kunst entstand, von verständigen SED-Genossen gedeckt und unterstützt, wurde geflissentlich übersehen.

Einen Bärendienst erwies diesen Vorurteilen 1999 anlässlich der Kulturhauptstadt Weimar eine unqualifizierte Ausstellung „Aufstieg und Fall der Moderne“ mit dem Ziel, alle DDRKunst unter Generalverdacht ideologischer Prägung und sie mit der NS-Auftragskunst in eine Reihe zu stellen. Der Kurator dieser Ausstellung, ein Architekturkritiker, erschien eines Tages im Kunstfonds des Freistaates Sachsen und und verlangte 400 Gemälde, „egal welche“. Deren Präsentation auf schwarzer Folie und die absichtsvoll lieblose Hängung förderte die Häme gewaltig. Minister Prof. Hans Joachim Meyer reiste inkognito nach Weimar und reagierte sehr zornig. Deshalb begrüßte er einen Dialog in Leipzig, als bei einer großen Runde von Fachleuten aus West und Ost eine sachliche Diskussion über die vielen Missverständnisse ihren Anfang nahm. Wie schwierig sich mancher im Westen anstellte, hat Hans Joachim Meyer eindrücklich in seinen Erinnerungen beschrieben: „Freilich hatte dieser Schritt [die Einheit] für die Beziehungen zwischen Ost und West innerhalb des dann vereinigten Deutschlands erhebliche und bis heute nachklingende Folgen. Denn die tatsächlichen wie die geistigen Unterschiede aus vierzig Jahren verschwanden ja nicht mit der Einheit. Und je mehr man diese Wirklichkeit zu ignorieren versuchte oder klein redete, umso gravierender sollte ihre Wirkung werden."

Aus allen möglichen öffentlichen Gebäuden, aus Partei- und Gewerkschaftszentralen, aus Betrieben und „Ferienobjekten“ war ein ziemlich großes Konvolut Bildender Kunst der DDR als "Sondervermögen“ beim Bundesfinanzministerium zusammengekommen, und die Länder wurden eingeladen, um den weiteren Verbleib der Kunstwerke zu klären. Mit meiner Referentin für Bildende Kunst, Sonhild Burghardt, bin ich wohl sechsmal nach Berlin gefahren: Wir wurden peinlich befragt, ob wir die Absicht hätten, ein Mausoleum von DDRKunst zu schaffen, was wir guten Gewissens verneinten. Mit Herbert Schirmer, dem letzten DDR-Kulturminister in der Regierung de Maizière, kamen wir schließlich überein, zwei Sammlungszentren zu bilden: für Mecklenburg-Vorpommern, Brandenburg und Berlin auf Schloss Beeskow, das Schirmer zu einem Zentrum zeitgenössischer Kunst ausbaute. Für Sachsen-Anhalt, Thüringen und Sachsen übernahm der Kunstfonds des Freistaates Sachsen die Titelaufnahme und Katalogisierung auf einer CD-ROM, die allen Museen zur Verfügung gestellt wurde. Das Depot richtete uns das Finanzministerium auf der Festung Königstein ein, wo die Kunstwerke garantiert sicher lagerten. Anschließend konnte interessierte Museen ihren Bedarf anmelden und die Kunstwerke übernehmen.

Der Kunstfonds des Freistaates hat aber auch die angenehme Aufgabe, alle staatlichen Büros bis hin zu den Amtsgerichtsstuben in Zwickau oder anderswo mit Kunstwerken auszustatten. In meinem Dienstzimmer hing ein wunderschönes Gemälde von Gerda Lepke, das ich nur ein Jahr lang entbehren musste, weil es während der sächsischen Präsidentschaft der Kultusministerkonferenz in deren Zentrale nach Bonn ausgeliehen wurde.

\section{Zeitgenössische Kunst und Kultur sowie musische Bildung}

Auch wenn Sachsen kein Filmland von der Potenz Hamburgs oder Nordrhein-Westfalens ist, so gehörte es zu den Aufgaben der Kunstabteilung und der Filmreferentin Hedda Gehm sowohl die Filmautoren, die Filmfestivals (an erster Stelle das Leipziger Dokumentarfilmfestival neben kleineren Veranstaltungen auch an der Peripherie) und die Kinos selbst zu unterstützen. Der MDR sah es nicht als seine vor- 


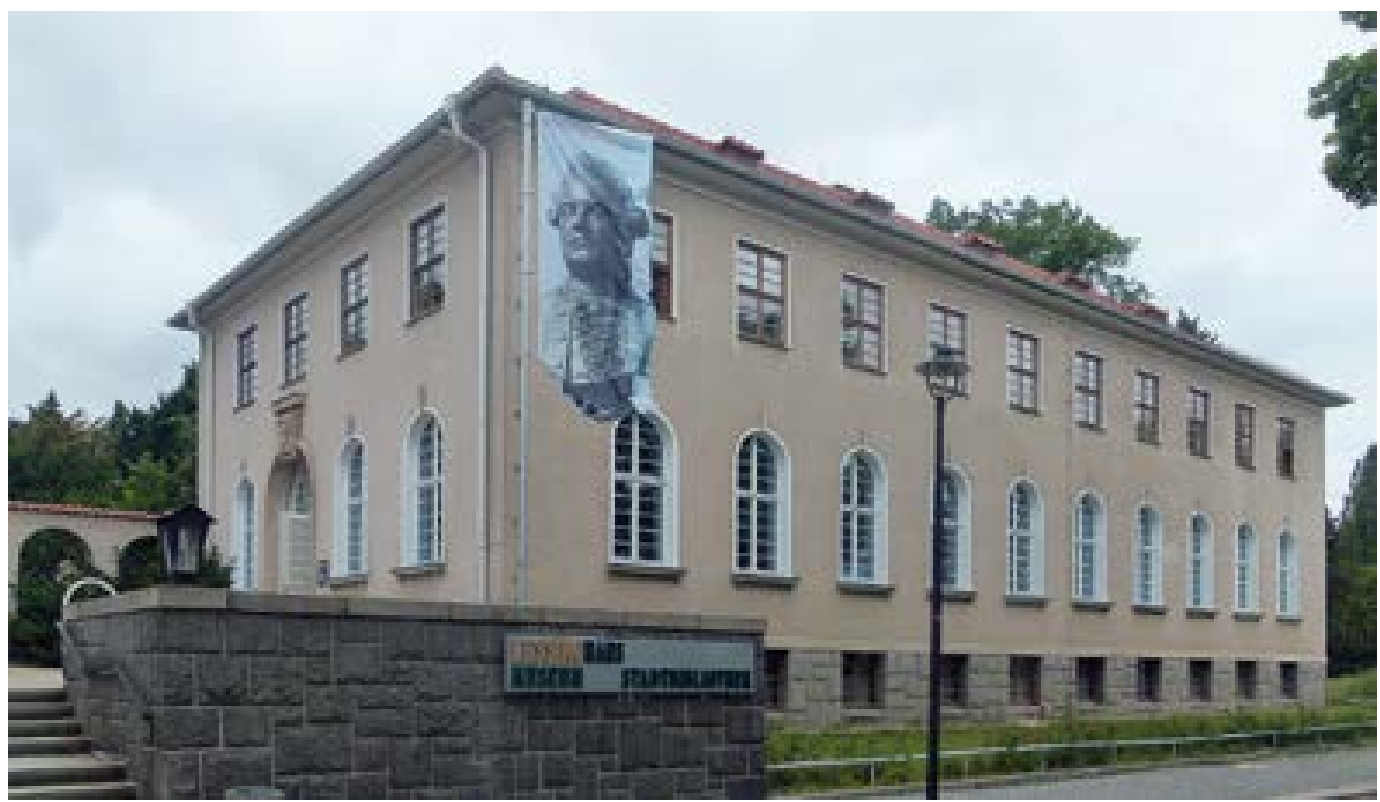

dringliche Aufgabe an, sächsischen Autoren Sendezeit zur Verfügung zu stellen, aber mit Hilfe der Sächsischen Landesmedienanstalt und anderer Fördermaßnahmen konnten viele interessante Streifen entstehen. Für die Kinos war es wichtig, sich durch Anschaffung von Digitaltechnik auf moderne Vorführweisen einzustellen, zumal in dem gesellschaftlichen und ökonomischen Umbruch Kinos in kleineren Gemeinden oft die letzte Kulturstätte waren. Auch hierfür stellte das SMWK Fördermittel bereit. Da bekanntlich in Dresden das Defa-Trickfilmstudio bis 1990 seinen Sitz hatte, bestand die Notwendigkeit, alle Produktionen $\mathrm{zu}$ archivieren. Diese Aufgabe übernahm das Deutsche Institut für Animationsfilme (DIAF), dessen Arbeit vom Filmreferat des SMWK unterstützt wurde.

Mit der Gründung des Literaturinstituts in Leipzig hatte die DDR-Kulturpolitik ein Zeichen ihrer Einflussnahme auf die „gefährlichste" aller Kunstgattungen, eine stets verfügbare Literatur, gesetzt. Das SMWK stand vor der Aufgabe, über den Fortbestand zu entscheiden und bekannte sich zu dieser Einrichtung, natürlich unter neuen Bedingungen und neuer Leitung. Neben dieser Spitze der Literaturentwicklung war es indessen notwendig, das Interesse an Literatur sowohl durch die Anschaffung neuer Literatur in öffentlichen Bibliotheken als auch durch viele Maßnahmen der Leseförderung zu unterstützen. So gelang es, das ehemalige Kornhaus in Zittau, das ein Investor $\mathrm{zu}$ einer Hochgarage umbauen wollte, als ein Haus der Literatur mit mehrstöckiger Bibliothek einzurichten.

In Kamenz wird seit 1993 aller zwei Jahre der Lessing-Preis des Freistaates Sachsen als Fort- setzung des 1955 begründeten Lessing-Preises der DDR verliehen. Er besteht aus einem Hauptpreis, der herausragende Leistungen im Geiste Lessings auf dem Gebiet der Literatur, der Literaturkritik und des Theaters würdigt. Zusätzlich werden zwei Förderpreise vergeben. Die Verleihung erfolgt meist am Vorabend von Lessings Geburtstag am 22. Januar im Rahmen der Lessing-Tage. Die Arbeit der Jury wurde von der Literaturreferentin Renate Brendel jeweils gründlich vorbereitet und begleitet.

$\mathrm{Zu}$ den angenehmen, wenn auch oft diplomatisch-heiklen Aufgaben gehörte es, das Protokoll der Staatsregierung bei der Gestaltung von offiziellen Feiern zu beraten. Ich bin noch heute stolz darauf, in den Festakt zur deutschen Einheit am 3. Oktober 2000 auch ein Werk der zeitgenössischen Musik eingeschmuggelt $\mathrm{zu}$ haben. Zwischen den Reden von Bundespräsident Johannes Rau, von Staatspräsident Jacques Chirac und anderen, die alle die Zeit überzogen, erklangen nicht nur Chorwerke des Thomanerchors und die „Freischütz“-Ouvertüre von Weber, sondern auch das Flötenkonzert des Berliner Komponisten Siegfried Matthus. Da die Sächsische Staatskapelle unter ihrem Chefdirigenten Giuseppe Sinopoli sich zu diesem Festakt präsentieren konnte, gewann ich zum Ausgleich drei Wochen später das Leipziger Gewandhausorchester für ein Festkonzert im Berliner Schauspielhaus, das der Ministerpräsident Kurt Biedenkopf zum Abschluss seiner Präsidentschaft als Bundesratsvorsitzender am 19. Oktober $2000 \mathrm{zu}$ geben beabsichtigte.

Der scheidende Präsident hielt eine kurze KonKunst vorbereitet wurde, und verwies darauf, dass bei der Gründung des Gewandhausorzerteinführung, die nicht in der Abteilung
Lessing-Museum in Kamenz Foto: wikimedia, Brücke-Osteuropa 
Schloss Colditz, heute Sitz der Landesmusikakademie des Freistaats Sachsen Foto: bennert-monumedia chesters 1781 hinter jedem Musiker ein vermögender Kaufmann stand, was heute die Finanzierung der sächsischen Kultur sehr erleichtern würde. Allerdings bei einer Stärke von 185 Musikern sind gegenwärtig schwerlich so viele finanzkräftige Kaufleute zu finden.

Alle Länder und der Bund haben einen Sitz im Stiftungsrat der Stiftung Preußischer Kulturbesitz. Wir nahmen die Sitzungen ernst, weil es schließlich um national bedeutendes Kulturgut ging, das auf der Berliner Museumsinsel und an anderen Orten präsentiert wird. Die Mitgliedschaft Sachsens im Stiftungsrat kam so zustande: Im Mai 1991 wurde ich auf den Fluren der Staatskanzlei angesprochen, ob denn Sachsen, beim immerwährenden latenten Kriegszustand mit Preußen, dieser Stiftung beitreten solle. Ich erklärte, dass die Preußen die Autographen des mitteldeutschen Komponisten Johann Sebastian Bach (Eisenach, Mühlhausen, Weimar, Köthen, Leipzig) auf das Pfleglichste bewahren, und dazu könne Sachsen auch einen Beitrag leisten. Damit war die Mitgliedschaft beschlossen.

Eines Tages erläuterte mir ein junger Instrumentenforscher, dass Heinrich Schütz 1628 bei einer seiner Italienreisen im Auftrag des Kurfürsten in der Stadt Cremona die modernsten
Streichinstrumente von Stradivari und Amati für die Hofkapelle bestellen hatte. Von dem damals großen Posten Instrumente haben einige Exemplare die Zeitläufte überstanden. Darunter eine Amati-Bratsche, die nach 1945 über private Kanäle so lange hin- und hergeschoben wurde, bis sie Anwalt Wolfgang Vogel im Auftrag der DDR-Regierung für 200.000 DM an die Stiftung Preußischer Kulturbesitz verkaufte. Als die Berliner Kollegen das Instrument von der Rückseite besahen, entdeckten sie den Brandstempel „Churfürstl. Capelle“ und verständigten das DDR-Kulturministerium, das keinerlei Interesse zeigte, weil Devisen wichtiger waren. Mit diesem Wissen begann ich Verhandlungen mit dem Geschäftsführenden Direktor der Stiftung, die schließlich zum Rückkauf führten. Heute wird das Instrument in Kirchenmusik-Aufführungen in der Dresdner Kathedrale gespielt.

Im Germanischen Nationalmuseum in Nürnberg haben der Bund, der mitfinanziert, und je zwei Länder einen Sitz, neben dem Freistaat Bayern und der Stadt Nürnberg. Im Verwaltungsrat, dem Entscheidungsgremium, sind außerdem Vertreter der Bayrischen Staatsmuseen, der beiden Konfessionen, des Hauses Wittelsbach und der Bürgerschaft aus Nürn-

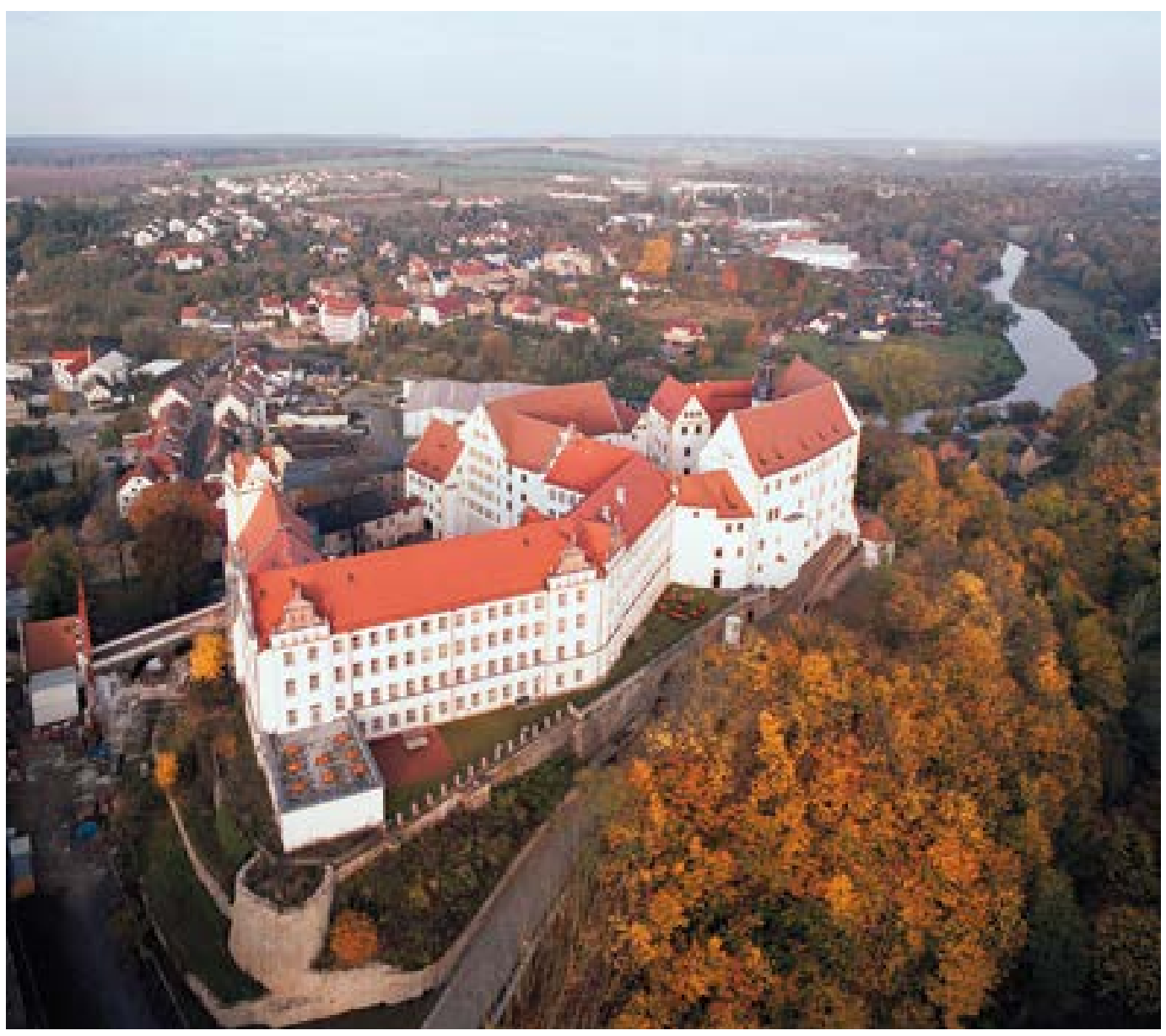


berg hinzugezogen. In meiner ersten Sitzung wurde ich mit einem Plan der Museumsleitung konfrontiert, eine Ausstellung mit Werken von Willi Sitte, dem ehemaligen Präsidenten des DDR-Verbandes Bildender Künstler, vorzubereiten. Das Museum sammelt, neben vielen Zeugnissen deutscher Geschichte, auch Nachlässe zeitgenössischer Künstler und wollte seine Reihe der neu erworbenen Künstler aus dem Osten Deutschland ausgerechnet mit Sitte beginnen, was einige sächsische Künstler veranlasste, über die Rückforderung ihrer Dokumente nachzudenken. Sitte hatte bereitwillig seine Aktenordner nach vorheriger gründlicher Reinigung übergeben und hoffte auf ein Signal aus Nürnberg. Dr. Bernhard von Loeffelholz, als Nürnberger Patrizier Mitglied im Verwaltungsrat, hatte gerade in der „Frankfurter Allgemeinen Zeitung“ über Machenschaften der Stasi gegenüber dem Dresdner Maler Eberhard Göschel berichtet, in dessen Zusammenhang auch die Rolle Sittes erwähnt wurde. Das Ganze drohte sich zu einem politischen Skandal auszuwachsen, was dem Vorsitzenden des Verwaltungsrates, dem ansonsten sehr selbstbewussten bayerischen Wissenschaftsund Kunstminister Hans Zehetmair, sehr missfiel. Es gelang schließlich nach komplizierten Debatten, einen Kompromiss auszuhandeln, nach dem zunächst eine wissenschaftliche Konferenz das Umfeld Sittes durchleuchten sollte, um dann über die Ausstellung zu entscheiden. Inzwischen hatte Sitte aber diese selbst abgesagt. Die Wissenschaftliche Konferenz, auf der ich das Eröffnungsreferat über Kunst und Bürokratie in der DDR hielt, zeichnete sich durch aberwitzige Diskussionen aus: So leugnete eine Professorin aus Münster die Existenz der Staatssicherheit im Kunstbereich der DDR generell. Das kam bei den ostdeutsche Teilnehmern gar nicht gut an.

Nicht an den Nachwuchs zu denken, wäre ein fahrlässiges Unterfangen und würde einer nachhaltigen Kulturpolitik die Basis entziehen. So dachte ich darüber nach, ob denn nicht, wie in der DDR, Künstler und Schulen besser zusammenwirken könnten. Ich entwickelte ein Konzept „Musische Bildung“, das in der Öffentlichkeit als „musikalische Bildung“ missverstanden und als überflüssig erachtet wurde, führte viele Gespräche mit interessierten Künstlern und gewann vor allem die Abgeordneten des Sächsischen Landtages im Schulausschuss für dieses Projekt. Danach sollten in den Nachmittagsstunden bestimmte praktische Kunsttechniken weit über den dürftigen Kunstunterricht hinaus vermittelt werden. Ich hatte indessen nicht mit dem erbitterten Widerstand des Kultusministers gerechnet, der sich bei Minister Prof. Hans Joachim Meyer über mein „Wildern“ auf fremdem Gebiet beklagte und das ganze Projekt in Minutenschnelle absagte. Heute ist das Ganztagsangebot, das dieses musische Angebot einschließt, an den Schulen Normalität. Der Sächsische Kultursenat hat seinerseits die Bildung eines Netzwerkes in der Oberlausitz angeregt und begleitet, das ebenfalls die musische Bildung in den Schulen betrifft.

Auch ein anderes Projekt der musischen Bildung konnte ich nicht durchsetzen: die Gründung einer Landesmusikakademie. Das Finanzministerium bot zwar das riesige Schloss Colditz an, da ich aber fürchtete, dass es so viele musizierende Schüler und Studenten in Sachsen gar nicht gibt, die gefühlten 200 Schlossräume zu füllen, lehnte ich diese Immobilie ab. Doch 2010 gelang der Musikreferentin des SMWK, Rodica Tines, in einem Flügel des Schlosses die Landesmusikakademie unterzubringen; außerdem zog dort noch eine Jugendherberge ein, wodurch sich die Belegung und der Betrieb beider Einrichtungen wesentlich günstiger gestalteten.

Vieles muss hier unerwähnt bleiben: die gemeinsamen Anstrengungen der Länder um den Erhalt der auch in den westdeutschen Kommunen gefährdeten Theater, die Bemühungen, den Deutschen Musikrat vor der Auflösung zu bewahren, der vergebliche Versuch, die mitteldeutschen Länder zu engeren Arbeitsbeziehungen zu veranlassen, und vieles andere mehr.

\section{Ausblick}

In den ersten 10 Jahren des Freistaates konnten somit Grundlagen geschaffen werden, die die Bewahrung und die gedeihliche Entfaltung des künstlerischen und kulturellen Potentials in Sachsen unterstützten. Ohne den politischen, moralischen und menschlichen Rückhalt des Staatsministers Prof. Dr. Hans Joachim Meyer wären viele Entscheidungen nicht in der beschriebenen Weise möglich gewesen. Er hatte am 13. November 1997 in der Regierungserklärung Kultur: „Kultur und Gesellschaft - Kulturpolitik aus demokratischer Verantwortung“ im Sächsischen Landtag Rechenschaft über die bis dahin geleistete Arbeit gegeben und einen Ausblick gewagt: Sachsen ist ein Kulturland sui generis. Wer dessen Grundlagen infrage stellt oder zu wenig für seine Entwicklung tut, der hat nichts begriffen von dem Geist, der in dieser Kulturlandschaft und ihren Gestaltern lebt. Nach der anfänglichen Phase bis etwa 2002, in der unsere Fachkompetenz das wichtigste politische Instrument war, scheint Kulturpolitik gegenwärtig wohl eher dazu zu dienen, damit Juristen verfahrenstechnische Sachverhalte klären können.

Es ist daher zu hoffen, dass darüber die Weiterentwicklung der sächsischen Kulturlandschaft nicht vernachlässigt wird.

\section{Autor}

Dr. Reiner Zimmermann 1991 bis 2003 Abteilungsleiter Kunst im Sächsischen Staatsministerium für Wissenschaft und Kunst Kreischa 